\title{
Comparison of aircraft-derived observations with in situ research aircraft measurements
}

Article

Accepted Version

Mirza, A. K., Ballard, S. P., Dance, S. L., Maisey, P., Rooney, G. G. and Stone, E. K. (2016) Comparison of aircraft-derived observations with in situ research aircraft measurements. Quarterly Journal of the Royal Meteorological Society, 142 (701). pp. 2949-2967. ISSN 1477-870X doi: https://doi.org/10.1002/qj.2864 Available at https://centaur.reading.ac.uk/65960/

It is advisable to refer to the publisher's version if you intend to cite from the work. See Guidance on citing.

To link to this article DOI: http://dx.doi.org/10.1002/qj.2864

Publisher: Royal Meteorological Society

All outputs in CentAUR are protected by Intellectual Property Rights law, including copyright law. Copyright and IPR is retained by the creators or other copyright holders. Terms and conditions for use of this material are defined in the End User Agreement. 


\section{CentAUR}

Central Archive at the University of Reading

Reading's research outputs online 


\title{
Comparison of aircraft derived observations with in situ research aircraft measurements.
}

\author{
Andrew K. Mirza ${ }^{1,3}{ }^{*}$, Susan P. Ballard ${ }^{2}$, Sarah L. Dance ${ }^{3}$, Paul Maisey ${ }^{1}$, Gabriel G. \\ Rooney $^{1}$, and Edmund K. Stone ${ }^{1}$ \\ ${ }^{1}$ Met Office, Exeter, United Kingdom, EX1 3PB \\ ${ }^{2}$ MetOffice@Reading, Department of Meteorology, University of Reading, Reading, United \\ Kingdom, RG6 6BB \\ ${ }^{3}$ School of Mathematical and Physical Sciences, University of Reading,Reading, United \\ Kingdom, RG6 6BB \\ ${ }^{*}$ Corresponding author email: andrew.mirza@metoffice.gov.uk
}

June 2016

\begin{abstract}
Mode Selective Enhanced Surveillance (Mode-S EHS) reports are aircraft-based observations that have value in numerical weather prediction (NWP). These reports contain the aircraft's state vector in terms of its speed, direction, altitude and Mach number. Using the state vector, meteorological observations of temperature and horizontal wind can be derived. However, Mode-S EHS processing reduces the precision of the state vector from 16-bit to 10-bit binary representation. We use full precision data from research grade instruments, on-board the United Kingdom's Facility for Atmospheric Airborne Measurements, to emulate Mode-S EHS reports and to compare with derived observations. We aim to understand the observation errors due to the reduced precision of Mode-S EHS reports. We derive error models to estimate these observation errors. The temperature error increases from $1.25 \mathrm{~K}$ to $2.5 \mathrm{~K}$ between an altitude of $10 \mathrm{~km}$ and the surface due to its dependency on Mach number and also Mode-S EHS precision. For the cases studied, the zonal wind error is around $0.50 \mathrm{~ms}^{-1}$ and the meridional wind error is $0.25 \mathrm{~ms}^{-1}$. The wind is also subject to systematic errors that are directionally dependent. We conclude that Mode-S EHS derived horizontal winds are suitable for data assimilation in high-resolution NWP. Temperature reports may be usable when aggregated from multiple aircraft. While these reduced precision, high frequency data provide useful, albeit noisy, observations; direct reports of the higher precision data would be preferable.
\end{abstract}

Keywords: aircraft observations; wind and temperature observations; high resolution NWP; Mode-S EHS error model; validation

\section{Introduction}

Mode Selective Enhanced Surveillance (Mode-S EHS) is used by Air Traffic Management (ATM) to retrieve routine reports on an aircraft's state vector at a high temporal frequency (every 4 to 12 seconds). The state vector consists of true-airspeed, magnetic-heading, ground-speed, ground-heading, altitude and Mach number. Mode-S EHS reports can be used to derive estimates of the ambient air temperature and horizontal wind at the aircraft's location (de Haan, 2011). These derived observations have the potential to give weather information on fine spatial and temporal scales. For example high-frequency reporting of vertical profiles of temperature and wind may provide extra information for use in numerical weather prediction (NWP) assimilation and nowcasting (Dance, 2004; Rennie et al., 2011; Sun et al., 2014; Ballard et al., 2015; Simonin et al., 2014). Indeed, positive impacts assimilating Mode-S data in regional numerical weather prediction (NWP) models have already been seen by several authors (de Haan and Stoffelen, 2012; de Haan, 2013b; Strajnar et al., 2015; Lange and Janjic, 2015). To maximize the potential of these data, it is important to understand the error characteristics of the derived observations.

Nowcasting weather phenomena such as thunderstorms, wind shear, low visibility conditions (fog and low cloud) and boundary layer evolution is of great interest to the aviation community (Montmerle, 2014) to aid tactical management of aircraft, especially within the vicinity of airports. The current method of receiving aircraft-based observations commonly used in NWP is from the Aircraft Meteorological Data Relay program (AMDAR) (Stickland and Grooters, 2005). AMDAR reports the horizontal wind and ambient temperature 
obtained from the aircraft's flight management systems (FMS) (Painting, 2003). These reports are compiled on-board the aircraft and are transmitted to a ground station. The frequency of transmission depends on the phase of flight and whether the aircraft is configured to send a report. By default, during ascent reports are every 6 seconds for the first 90 seconds then every 20 seconds until level flight; during level flight reports are every 3 to 10 minutes; during descent reports are every 60 seconds (Painting, 2003, p.32). In Europe this program is managed by E-AMDAR which provides to National Meteorological Services only one profile once every three-hours at a mainland airport. The Met Office, the United Kingdom's national weather service, obtains one profile once every hour at major airports. This contrasts with ATM which can interrogate an aircraft's transponder from a ground station using Secondary Surveillance Radar (Boisvert and Orlando, 1993) at much higher frequency. Depending on the type of interrogation and transponder, the transponder sends back an aircraft's identification code (MODE-A), altitude information (MODE-C) or more detailed information (Mode-S EHS).

The contents of Mode-S reports depend on what is requested by ATM and this varies from country to country (International Civil Aviation Organisation, 2010). There are three types of reports from which meteorological observations may be obtained:

(a) Mode-S EHS reports contain information on the aircraft's state vector. This vector can be used to derive estimates of the air temperature and horizontal wind at the aircraft's location (Collinson, 2011; de Haan, 2011).

(b) Mode-S Meteorological Routine Aircraft Reports (MRAR) contain temperature and horizontal wind observations computed by the aircraft's FMS (Strajnar, 2012).

(c) Automatic Dependent Surveillance Broadcast (ADS-B) (a sub-system of Mode-S EHS) contain aircraft position and altitude from which a mean temperature and wind vector may be computed (de Leege et al., 2012; Stone and Kitchen, 2015).

Whilst Mode-S MRAR provides direct reports of temperature and horizontal wind observations the regulatory environment does not require aircraft or ATM to make such reports available. The most common report is the Mode-S EHS aircraft's state vector from which temperature and horizontal wind observations are derived.

Previous studies, discussed in more detail in section 2, have compared AMDAR reports with observations made using radiosondes or other nearby aircraft (Schwartz and Benjamin, 1995; Benjamin and Schwartz, 1999 ; Drue et al., 2008). Similar studies have compared Mode-S EHS (de Haan, 2011) and Mode-S MRAR (Strajnar, 2012) also with radiosonde and nearby AMDAR reporting aircraft. However, observations are not co-located in time and space. Furthermore, studies by Ballish and Kumar (2008); Drue et al. (2008); de Haan (2011); Jacobs et al. (2014) indicate that aircraft reports have additional error sources that are aircraft-type specific and which affect the temperature and horizontal wind vector reports. While these studies provide useful information about aircraft-based observations, it is not clear how to partition the errors between the variability due to the aircraft, its instruments, processing algorithms and the atmosphere.

The new work in this paper investigates the errors of Mode-S EHS derived observations resulting from the limited precision of the transmitted aircraft state vector. We do this using in situ recordings made with research-grade high precision instruments aboard the Facility for Atmospheric Airborne Measurements (FAAM BAe-146) (Smith and Gratton, 2004). Unfortunately the FAAM aircraft does not have a Mode-S transponder so we emulate the processing of the aircraft's state vector, using the in situ research observations, so as to generate Mode-S EHS type reports. We then derive the temperature and wind and compare with the actual in situ observations. We also derive an error model based on a consideration of Mode-S EHS processing and validate this model using the in situ observations.

This paper is organized as follows: in section 2 we review previous studies assessing the accuracy of meteorological observations reported by aircraft. In section 3 we describe the data contained in a Mode-S EHS report and how we emulate the reports using data recorded by the FAAM BAe-146. We also show how the horizontal wind and the ambient temperature are obtained. Section 4 describes the instruments used to obtain the in situ observations and details the six case studies to be examined. In section 5 we evaluate one case study in detail to describe the methodology used for the analysis. We derive and apply an error model for the Mode-S EHS processing. Section 6 presents the results for all of the cases studied, which suggest that observation error for temperature due to the reduced precision the aircraft's state vector is up to $4.5 \mathrm{~K}$, an order of magnitude greater than AMDAR's $0.4 \mathrm{~K}$ (Painting, 2003). For the cases studied, the observation error for horizontal wind due to the reduced precision is up to $0.5 \mathrm{~ms}^{-1}$ compared with AMDAR's 2 to $3 \mathrm{~ms}^{-1}$ (Painting, 2003). Section 7 summarizes the findings of this work and concludes that horizontal wind derived from Mode-S EHS observations may have practical applications for high-resolution NWP, while derived temperatures may be aggregated from multiple aircraft to provide useful information. However, this requires further investigation to assess how to minimize their errors. Finally, in light of the findings in this paper,we note that direct reports of higher precision data would be preferable. 


\section{Accuracy of aircraft-based observations}

In this section we review previous studies that assessed the accuracy and precision of aircraft-based observations. We assess the level of agreement between these studies and summarize their limitations.

A number of studies have been performed to obtain estimates of the accuracy of aircraft-based meteorological reports. This has been done by comparing aircraft-based reports to nearby reports made by radiosonde and other reporting aircraft (Schwartz and Benjamin, 1995; Benjamin and Schwartz, 1999; Painting, 2003; Drue et al., 2008; de Haan, 2011; Strajnar, 2012) or by comparison to NWP models (Cardinali et al., 2003; Ballish and Kumar, 2008; de Haan, 2011; de Leege et al., 2012). de Haan (2015) uses a triple collocation method with Doppler radar, sodar and NWP data. Tables 1 and 2 summarize the results of these studies for root-meansquare-error (RMSE) and mean-bias (MB) respectively, and show fairly consistent results between studies. In particular, de Haan (2011) concludes that the accuracy of Mode-S EHS derived horizontal wind, after preprocessing the aircraft state-vector, is comparable with similar reports from AMDAR but is less accurate when compared with radiosonde. Mode-S EHS derived temperature is less accurate when compared with radiosonde and AMDAR. In addition, the RMSE for temperature is twice as large as that for AMDAR. Strajnar (2012) concludes that the accuracy of Mode-S MRAR directly reported horizontal wind is comparable with similar reports from AMDAR but is less accurate when compared with radiosonde.

A number of other features of aircraft-based observation errors have also been identified. Temperature biases have been found to vary with altitude (Schwartz and Benjamin, 1995; Benjamin and Schwartz, 1999; Drue et al., 2008; Ballish and Kumar, 2008), with errors decreasing as height increases. The large errors near the surface are thought to be due to extra mesoscale variability in the boundary layer and lower troposphere. Schwartz and Benjamin (1995); Drue et al. (2010) also found differences between temperature reports from ascending and descending aircraft, thought to be caused by changes in the aircraft's wing configuration. They may also be due to sensor response time or AMDAR processing of temperature data aboard the aircraft or some combination of the two. There is also evidence for temperature biases that are aircraft-type specific (Ballish and Kumar, 2008). Drue et al. (2008) found systematic errors in the wind reports which appear dependent on the aircraft's heading and aircraft type; there are similar findings by de Haan (2011) and Jacobs et al. (2014). The horizontal wind errors are due to a directionally dependent systematic error. de Haan (2013a) considered a Mode-S EHS error analysis with respect to NWP and found that heading corrections only affect wind-components transversal to the aircraft's direction of travel. de Haan (2011) introduced a heading correction based on landing aircraft. These values are comparable to the NWP-based corrections (de Haan, 2013a).

These previous studies have their limitations. For example, there are only one or two radiosonde launches per day, typically at 00 UTC and 12 UTC, at limited locations. Therefore, comparisons with co-located radiosondes are very limited in time and space providing only a short time window when aircraft might be close by (as shown in tables 1 and 2). Direct comparison of Mode-S EHS with AMDAR is limited to those reporting aircraft that participate in the AMDAR programme and which are configured to send reports. In addition, at present, the mapping between Mode-S EHS identifiers and AMDAR identifiers is not straightforward. Not all airlines make tail numbers available. Thus some additional computational steps are required to co-locate reports using a space-time box but this method of pairing is not robust. This is particularly true in busy areas where Mode-S EHS and AMDAR reports at similar locations and times will not necessarily originate from the same aircraft. The limitations of NWP based studies include the need to take account of uncertainties in the NWP model and observations used, including representativity errors (Daley, 1991, p.12; Waller et al., 2014), NWP forecast errors etc.

Using existing aircraft reports it is difficult to differentiate the contributions to the observation error arising from the aircraft's sensors, avionics processing and atmospheric variability. The new work in this study provides insight into contributions arising from reduced precision in Mode-S EHS reports.

\section{Aircraft Data and the emulation of Mode-S EHS messages}

In this section we describe the aircraft platform used to collect aircraft data (subsection 3.1); how the aircraft data are represented by aircraft's subsystems (subsections 3.2 and 3.3); how the FAAM core data are used to emulate Mode-S EHS messages (subsection 3.4); and how the aircraft state vector is used to derive temperature and the horizontal wind vector (subsections 3.6 and 3.7).

\subsection{Facility for Atmospheric Airborne Measurements (FAAM BAe-146)}

The United Kingdom's (UK) National Centre for Atmospheric Science (NCAS) operate an aircraft, a modified BAe 146-301, for atmospheric research called the Facility for Atmospheric Airborne Measurements (FAAM BAe146) (Smith and Gratton, 2004). This facility provides an aircraft measurement platform for use by the UK atmospheric research community on research campaigns throughout the world. The aircraft carries research- 
grade instruments to make measurements for a particular research campaign. These data are recorded every second whilst the aircraft is in flight and at 32-bit floating point precision. Note this is not intended to indicate the precision of the actual research instrument. Two parameters, pressure altitude and indicated airspeed, are recorded from the flight management system via a network interface card that uses the Aeronautical Radio Incorporated (ARINC) 429 Standard.

\subsection{Aeronautical Radio Incorporated (ARINC) 429 Standard}

A network protocol is used to transfer data between aircraft subsystems. The network protocol used aboard the FAAM is the Aeronautical Radio Incorporated (ARINC) 429 standard ( Airlines Electronic Engineering Committee, 2004; Spitzer, 2006, Ch. 2). The network protocol defines how data are transferred in the form of data packets. An ARINC 429 data packet is a 32-bit binary number, of which 20 binary bits are available for representing data; label information to indicate the content of the data packet uses 8 binary bits; the remaining binary bits are available to indicate the validity and quality of the data in the packet. The actual number of binary bits used to represent data is determined by consensus among the original equipment manufacturers, then published as an aeronautical standard. If this number is less than 20 binary bits then the unused bits may be re-purposed, for example to store data to a higher level of binary precision during computation. Using the ARINC-429 standard, the data range, number of binary bits, and the data increment that are relevant for meteorological reporting are listed in table 3. (The network protocol will be aircraft-type specific, for example, contemporary aircraft may use the later edition of the standard, ARINC 629. An ARINC 629 data packet has 16 binary bits available for representing data.)

The data used for the aircraft state-vector are represented using an $n$-bit binary counter, where $n$ is the maximum number of binary bits. The data increment, $\epsilon$, is the decimal value of the least significant bit (LSB). This is defined as,

$$
\epsilon=d / 2^{n}
$$

where $d$ is the numerical range of the reported parameter and $2^{n}$ is the range of the counter expressed as a decimal integer. The precision of the data is taken to be $\pm 0.5 \times \epsilon$. For example, the ARINC-429 label 205 is for Mach number, $M$, and its numerical range is defined as $0 \leq M<4.096$. The binary counter used to represent this range is of length 16 binary bits, which provides a decimal integer range from 0 to $2^{16}$. The value of the LSB is then $\epsilon=4.096 / 2^{16}=0.00006250$. Thus the ARINC-429 Mach number precision is taken to be \pm 0.00003125 . For examples of how data can be represented using an $n$-bit binary counter see Begueret et al. (2008).

\subsection{The Mode-S EHS Message Format}

The Mode-S EHS message format (European Organisation for Civil Aviation Equipment, 2008) is used by the Mode-S EHS transponder to transfer data between aircraft subsystems and ground-based subsystems and is part of the secondary surveillance radar system (Boisvert and Orlando, 1993). The precision of the data contained in a Mode-S EHS message is lower than that of the ARINC-429 data packet. Table 3 shows that most of the parameters relevant for meteorological reporting are reduced from 16 binary bits to 10 binary bits representation. Thus the Mode-S EHS Mach number precision is \pm 0.002 .

A Mode-S EHS transponder reports an aircraft's state vector using the reduced precision parameters listed in table 3. These reports are retrieved by a secondary surveillance radar network operated by ATM. The maximum rate at which these reports are requested is determined to some extent by the rotation rate of the secondary radar; typically every 4 to 12 seconds. However, other factors may reduce the number of reports received, e.g., distance from the radar, air-traffic density and radio interference. Nevertheless, the number of reports received is at sufficiently high frequency to enable the ATM to perform their function of maintaining safe separation between aircraft. The parameters for the aircraft's state vector are stored within the Mode-S EHS transponder and updated, typically, every 1.3 seconds (International Civil Aviation Organisation, 2012).

\subsection{Emulation of Mode-S EHS messages}

The FAAM aircraft is not equipped with a Mode-S EHS transponder. Thus for this study Mode-S EHS reports for the aircraft's state vector were instead emulated using data recorded by the FAAM aircraft, although the actual transmission of the Mode-S EHS message was not emulated.

The parameters for the aircraft's state vector are drawn from the FAAM's recorded data. The Mode-S EHS ground-direction, ground-speed, magnetic-heading, latitude, longitude and time-of-report are obtained from the FAAM's global positioning system (GPS) and inertial navigation system (INS) (Woolley, 2008a; Applanix, 
2006). The pressure altitude was obtained from the aircraft's FMS. The Mach number, $M$, is calculated postflight using the equation (Collinson, 2011, pp. 392-395),

$$
\frac{Q}{P_{S}}=\left(1+0.2 M^{2}\right)^{\frac{7}{2}}-1,
$$

where $Q(\mathrm{hPa})$ is the pitot-static pressure difference and $P_{S}(\mathrm{hPa})$ the static pressure, obtained from the FAAM's turbulence probe Woolley (2014a). The true-airspeed was obtained by the following method: A pitot-static pressure difference was measured by the turbulence probe, from which a Mach number was obtained. This, along with the de-iced temperature measurement, was used to compute the true airspeed. Full precision data is used in these computations. More details about these sensors are given in section 4 .

Before being passed to a process that generates the Mode-S EHS message format, each parameter is converted from 32 binary bits floating point representation to 16 binary bits unsigned integer. This requires the Mach number to be expressed in the unit of milliMachs. The directional parameters are recast as follows:

(i) The data range of the ground-heading, $\theta_{G}$, is changed to $0^{\circ} \leq F\left(\theta_{G}\right)<360^{\circ}$, where

$$
F\left(\theta_{G}\right)= \begin{cases}\theta_{G} & : 0^{\circ} \leq \theta_{G}<180^{\circ} \\ \theta_{G}+360^{\circ} & :-180^{\circ} \leq \theta_{G}<0^{\circ} .\end{cases}
$$

(ii) The input true-heading, $\theta_{A}$, is converted to magnetic-heading, $\theta_{\text {mag }}$, using the 2010 World Magnetic Model (Maus et al., 2010), so that its data range is $0^{\circ} \leq F\left(\theta_{\text {mag }}\right)<360^{\circ}$, where

$$
F\left(\theta_{\text {mag }}\right)= \begin{cases}\theta_{\text {mag }} & : 0^{\circ} \leq \theta_{\text {mag }}<180^{\circ} \\ \theta_{\text {mag }}+360^{\circ} & :-180^{\circ} \leq \theta_{\text {mag }}<0^{\circ} .\end{cases}
$$

(The conversion between true-heading and magnetic-heading is discussed further in subsection 3.5.)

The algorithm used to convert the aircraft state parameters to the corresponding Mode-S EHS bit level precision is given in table 4. The algorithm is illustrated using an example computation for the Mode-S EHS Mach number. The effect of the algorithm is to round-up or round-down the input value by an amount such that the result is a multiple of the LSB for Mode-S EHS. (A similar algorithm is used for converting FAAM's core data to the corresponding ARINC-429 bit level precision.)

\subsection{Aircraft True-heading.}

In order to compute the horizontal wind-vector, the aircraft's true-heading, $\theta_{A}$, is required. This is the direction of the aircraft's longitudinal axis, where the angle of direction is measured clockwise from Geographic North. However, the Mode-S EHS report contains the aircraft's magnetic-heading, $\theta_{\text {mag }}$, which is the angle measured clockwise from Magnetic North. Geographic North and Magnetic North are not coincident and their separation varies over time and by location. In addition, the aircraft's true-heading may be subject to instrument error that depends on the type of heading-reference system being used for navigation (Mulally and Anderson, 2011; Jacobs et al., 2014). Thus, the aircraft's true-heading, $\theta_{A}$, is the sum of these components:

$$
\theta_{A}=\theta_{\text {mag }}+\theta_{v a r}+\theta_{d e v}
$$

where $\theta_{\text {var }}$, called the magnetic variation, takes account of the angular difference between Geographic and Magnetic North; and $\theta_{d e v}$, called the magnetic deviation (or the compass error), takes account of the remaining sources of error which include instrument errors in the heading reference system.

An aircraft's FMS applies the corrections for $\theta_{v a r}$ and $\theta_{d e v}$. The magnetic variation, $\theta_{v a r}$, is obtained from a look-up table based on the World Magnetic Model (WMM) (Maus et al., 2010). The WMM models the estimated variations in the Earth's magnetic field and is updated every five years. The aircraft's magnetic deviation, $\theta_{d e v}$, is obtained from calibration of the heading reference system against a reliable reference source, usually a high-precision gyro-scope (Civil Aviation Authority, 2013), and programmed into the FMS as a lookup table. (It should be noted that an FMS may be using outdated versions of the WMM (Nakamura, 2013; Weinstein, 2009) and compass calibrations are only required to be performed once every two to three years (Civil Aviation Authority, 2013).)

The FAAM INS reports true-heading, $\theta_{A}$. We assume that the INS is calibrated so that the magnetic deviation, $\theta_{d e v}$, is approximately zero. This is because the tables for magnetic deviation were unavailable. So for the purpose of this paper the magnetic-heading is emulated as, $\theta_{\text {mag }}=\theta_{A}-\theta_{\text {var }}$. 


\subsection{Deriving the ambient air-temperature from Mode-S EHS reports of Mach number and airspeed}

Following the method of de Haan (2011) the ambient air-temperature is derived from Mode-S EHS reports of Mach number and airspeed. The Mach number is defined as the ratio of the aircraft's airspeed $V_{A}$, and the local speed-of-sound, A, (Houghton and Carpenter, 2003) so that

$$
M=\frac{V_{A}}{A} .
$$

The magnitude of the local speed-of-sound is related to the local ambient temperature and is given by (Collinson, 2011, pp. 390-392),

$$
A=\sqrt{\gamma R_{a} T_{A}},
$$

where $\gamma$ is the ratio of the specific heats for dry air at constant volume and constant pressure; $R_{a}$ is the characteristic gas constant for dry air; and $T_{A}$ is defined as the local ambient temperature.

Using Eq. (7) we can relate the local ambient temperature to the Mach number and airspeed as follows,

$$
A=A_{0} \sqrt{\frac{T_{A}}{T_{0}}}=\frac{V_{A}}{M},
$$

where the speed-of-sound $A_{0}=340.294 \mathrm{~ms}^{-1}$ and the ambient temperature $T_{0}=288.15 \mathrm{~K}$ are constants defined at mean-sea-level pressure under standard atmosphere conditions (International Civil Aviation Organisation, 1993). So the ambient temperature can be recovered from the Mode-S EHS reports as

$$
T_{A}=\frac{T_{0}}{A_{0}^{2}}\left[\frac{V_{A}}{M}\right]^{2} .
$$

It is assumed that the ambient temperature does not contain effects of heating due to air compression within the housing of the temperature sensor or cooling due to evaporation of moisture from the temperature sensing element (Lawson and Cooper, 1990; Woodfield and Hayne, 1965).

\subsection{Deriving the Horizontal Wind Vector from the Mode-S EHS message}

In this section we show how the horizontal wind vector is derived from the Mode-S EHS message. We define the aircraft's air-vector, $\mathbf{V}_{\mathbf{A}}$, as the speed of the aircraft relative to the surrounding air, $V_{A}$, and its horizontal orientation in space, $\theta_{A}$. (In aviation terms these are the aircraft's 'true-airspeed' and 'true-heading.') We also define the aircraft's ground-vector, $\mathbf{V}_{\mathbf{G}}$, as its ground-speed, $V_{G}$, and ground-heading, $\theta_{G}$. These are the aircraft's speed and track projected onto the Earth's surface. (In aviation terms these are the aircraft's 'ground-speed' and 'true-track angle.')

We now show how the wind vector is derived. The horizontal wind-vector, $\mathbf{V}_{\mathbf{W}}$, is the vector difference between the aircraft's ground-vector and the aircraft's air-vector, i.e., $\mathbf{V}_{\mathbf{G}}-\mathbf{V}_{\mathbf{A}}$ (Painting, 2003, p. 11).

The horizontal wind-vector, $\mathbf{V}_{\mathbf{W}}$, is resolved into orthogonal components: a zonal component (West-East), $U$, and a meridional component (South-North), $V$. These are obtained by resolving the corresponding components of the air-vector, $\mathbf{V}_{\mathbf{A}}$, and ground-vector, $\mathbf{V}_{\mathbf{G}}$, along the South-North and West-East axes, so that,

$$
U=V_{G} \cos \left(\frac{\pi}{2}-\theta_{G}\right)-V_{A} \cos \left(\frac{\pi}{2}-\theta_{A}\right),
$$

and

$$
V=V_{G} \sin \left(\frac{\pi}{2}-\theta_{G}\right)-V_{A} \sin \left(\frac{\pi}{2}-\theta_{A}\right) .
$$

For these equations, the unit of angular measure for $\theta_{G}$ and $\theta_{A}$ is radians, although the Mode-S EHS reports use angular degrees. The angle $\pi / 2$ radians is equivalent to $90^{\circ}$. Using these wind components the wind speed and wind direction are determined.

It is assumed that the horizontal wind-vector lies within a 2-D horizontal plane which is parallel to a tangent plane drawn at the Earth's surface at the aircraft's latitude and longitude. Any vertical component to the wind-vector is small compared to the horizontal components.

\section{Meteorological research measurements}

The observation and reference data used in this study were recorded during the COnvective Precipitation Experiment (COPE) which took place during the summer of 2013 (Leon et al., 2015). The project's goal was to study the evolution of convective conditions within regions of the United Kingdom. In addition to data 
obtained during the COPE campaign, aircraft data were also obtained during scheduled flights for maintenance and instrument tests; including one flight for calibrating the International Sub-Millimetre Airborne Radiometer (Moyna et al., 2010). Table 5 lists the six flights used for this study along with a short description of each flight. A total of 21.7 hours of flight data were recorded for six flights of which 12.2 hours passed quality control processing. The weather conditions for these flights are described by Eden $(2013 \mathrm{a}, \mathrm{b})$.

Measurements of the horizontal components of the wind $\left(U_{R E F}, V_{R E F}\right)$ are obtained from the aircraft's fiveport pressure sensor located in the nose-cone of the aircraft. The centre port measures the static pressure. The wind-vector components are then determined by the pressure differential recorded by remaining four sensors. The methodology is described by Brown (2004) and Nicholls (1980). The method makes use of the aircraft's ground vector, as measured by the inertial navigation system. Corrections are made for the rotation of the aircraft around its pitch axis, which is an imaginary line that runs from wing-tip to wing-tip; and its yaw-axis, which is an imaginary line that runs vertically through the aircraft; both lines have their origin at the aircraft's centre of gravity.

Temperature is recorded by two Rosemount type 102B hot-wire thermometers located at the front starboard side of the aircraft's main body. One thermometer is heated to prevent icing. These thermometers record the total-air-temperature (Woolley, 2009; Stickney et al., 1994), which is the sum of the ambient temperature and the heating effect due air being compressed in the sensor's housing. During post-flight processing two ambient temperatures are recovered which are referred to as the de-iced and non-de-iced temperature (Woolley, 2008b). The aircraft's geographic position is recorded by an INS/GPS receiver. Reference time is taken from the INS/GPS receiver and is measured as the elapsed number of UTC seconds since the start of the day. In addition to these measured parameters, the aircraft's pressure altitude and indicated airspeed are obtained from the aircraft's FMS.

Once the aircraft has returned to its base of operations, the recorded data are post-processed to generate data at $1 \mathrm{~Hz}$. During post-processing the FAAM measurements are corrected for known instrument biases. The indicated air speed and pressure altitude are used as first-guess values for calibration when deriving the meteorological measurements for the horizontal and vertical winds, and ambient temperature. The expected accuracies of aircraft state parameters after post processing are shown in table 6 . The expected accuracies for the $U_{R E F}$ and $V_{R E F}$ obtained from the turbulence probe are assumed to be $\pm 0.2 \mathrm{~ms}^{-1}$. This assumption is based on the experiments carried out by Tjernstrãm and Friehe (1991) that used a similar turbulence probe on a Sabreliner 40A.

\section{$5 \quad$ Flight B787, $11^{\text {th }}$ July 2013.}

This section describes the results for one case study, flight B787, which took place on 11th July 2013. This will illustrate the method as subsequently applied to all the cases listed in table 5 . The prevailing weather conditions on this day saw a high-pressure region centred over the UK, resulting in light winds and very little cloud over the south-west region; daytime surface temperatures were approximately $13^{\circ} \mathrm{C}$ to $18^{\circ} \mathrm{C}$ and surface winds were light to moderate and in a North-Easterly direction. Figure 1 depicts the flight path of FAAM flight B787. This FAAM flight was chosen because its vertical profile is similar a flight profile to that of commercial aircraft which consists of three main phases: ascent, en-route and descent.

This flight was conducted over the Bristol Channel and consisted mostly of East-West trajectories; with staged ascents for the first half of the flight then staged descents for the second half. This is shown as the vertical profile in figure 2(a). The expected errors in pressure altitude due to departures from the ISA are \pm 8.0 $\mathrm{m}$ for altitudes between $0 \mathrm{~km}$ and $3 \mathrm{~km}$ and $\pm 30.0 \mathrm{~m}$ for altitudes above $3 \mathrm{~km}$ (Society of Automotive Engineers International, 1996). The flight segment from $09 \mathrm{~h} 10$ to $09 \mathrm{~h} 45$ was a low-level run for instrument calibration. Figure 2 (b) shows the corresponding static temperature variation for this flight profile recorded by the FAAM's de-iced temperature sensor, which has an accuracy of $\pm 0.3 \mathrm{~K}$. The temperature decreases smoothly as the altitude increases. Gaps in the profiles indicate regions where data are rejected. This occurs mostly during the ascent from $6 \mathrm{~km}$ to $10 \mathrm{~km}$. Data rejection is due mostly to unstable flight conditions or exceeding the quality control thresholds, which are listed in table 7; this process is described further in section 5.1.

\subsection{Quality Control of Input Data}

Quality control criteria are applied to the recorded data which filter out data for unsteady flight conditions or for gross errors (table 7). For reliable readings from the pitot-static sensor the aircraft needs to be moving and the air-flow around the body of the aircraft should be stable. The FAAM aircraft is considered to be in flight when its airspeed is $\geq 25 \mathrm{~ms}^{-1}$ and it has a stable air flow around the body of the aircraft when the absolute value of its roll-angle is less than $1.5^{\circ}$ (Woolley, 2014a). The quality control also removes turns and unusual manoeuvres conducted by the aircraft whilst in-flight. Gross error checks are included to ensure that sensible values are contained within the resulting data-set. These quality control criteria are similar to those used by 
Painting (2003); de Haan (2010, 2011). Where derived or reference observations fail the quality control criteria the corresponding data pairs are removed from the dataset.

\subsection{Notation and Metrics}

For discussion of the results the following notation are used to maintain the distinction between the derived and reference values. The static ambient temperature derived from the emulated Mode-S EHS report using Eq. (9) will be referred to as the Mach Temperature, $T_{M A C H}$. The reference observations are the FAAM's measurements of the static ambient temperature measured by the de-iced sensor which will be referred to as $T_{R E F}$. Zonal and meridional wind components are derived using the methods of section 3. The winds calculated using ARINC precision are referred to as $U_{A R I N C}$ and $V_{A R I N C}$ and those calculated using Mode-S EHS precision are referred to as $U_{M o d e-S}$ and $V_{M o d e-S}$. The corresponding reference wind components derived from the turbulence probe are referred to as $U_{R E F}$ and $V_{R E F}$.

An estimate of the sample standard deviation, $\sigma$, is obtained from the metrics of the mean bias $(M B)$ and root mean square error (RMSE) (Wilks, 2011; Jolliffe and Stephenson, 2012) using (Ross, 2009, p.271),

$$
R M S E^{2}=M B^{2}+\sigma^{2}
$$

where

$$
M B=\frac{1}{N_{f}} \sum_{i=1}^{N_{f}}\left(o_{i}-r_{i}\right),
$$

and

$$
R M S E=\sqrt{\frac{1}{N_{f}} \sum_{i=1}^{N_{f}}\left(o_{i}-r_{i}\right)^{2}} .
$$

The term $o_{i}$ is the $i^{\text {th }}$ Mode-S EHS derived observation, i.e., $T_{M A C H}, U_{M o d e-S}$ or $V_{M o d e-S}$, and the term $r_{i}$ is the corresponding REF observation matched by position and time, i.e., $T_{R E F}, U_{R E F}$ or $V_{R E F}$. The term $N_{f}$ is the number of observation and reference pairs that passed the quality control criteria given in table 7 . The uncertainty in the standard deviation is estimated by (Taylor, 1982, pp.294-298),

$$
\delta \sigma=\frac{\sigma}{\sqrt{2\left(N_{f}-1\right)}} .
$$

For comparing results we define a box-average. The pressure-altitude is divided into bins of height $0.3 \mathrm{~km}$ from the surface to $10 \mathrm{~km}$. The Mode-S EHS reports, Mode-S EHS derived observation and corresponding REF observation are sorted into the bins. For each bin, $\sigma, \delta \sigma$, MB and RMSE are computed and each result assigned to the centre of each bin. In addition, the mean values of Mode-S EHS reports are computed and the result assigned to the centre of the bin. The results assigned to the centre of each bin are referred to as the box-average.

\subsection{Quality of Derived Mach Temperature}

In this section we analyse the vertical profile of the temperature difference $T_{M A C H}-T_{R E F}$. An error model is derived to estimate the observed differences and we suggest that the differences are dominated by the effect of Mode-S EHS processing. We also use the error model to estimate the precision of the derived temperature, $\Delta T$, for three levels of Mode-S EHS data precision.

\subsubsection{Differences in $T_{M A C H}$ and $T_{R E F}$}

Figure $3(\mathrm{a})$ is the vertical profile of $T_{R E F}$ for the whole flight recorded by the FAAM de-iced temperature sensor. At the start of the flight there was a low level temperature inversion which had dissipated by the end of the flight. This can be seen as the two intercepts at the surface. Figure $3(\mathrm{~b})$ is the vertical profile of $T_{M A C H}$ computed using Eq. (9). This profile shows the effects of Mode-S EHS processing. Firstly a distinct temperature inversion cannot be seen in the figure due to the spread in the data. Restricting the data plotted to the early part of the flight indicates that this is still a feature of the derived measurements (not shown). Secondly, there is an apparent double profile between $7 \mathrm{~km}$ and $9 \mathrm{~km}$; it was found that the reduced precision of the Mach number causes $T_{M A C H}$ to oscillate between two values resulting in the double profile. Figure 3(c) is the temperature difference profile $T_{M A C H}-T_{R E F}$. These are magnitudes of the differences that range from $6 \mathrm{~K}$ near the surface to $3 \mathrm{~K}$ at high altitude. (The grey profile is discussed in section 5.3.2.) Figure 3(d) depicts the distribution of these differences as a histogram which appears to be approximately symmetric and uni-modal in form, with a sample mean $0.029 \mathrm{~K}$ and a sample standard deviation $2.14 \mathrm{~K}$. 


\subsubsection{Estimated Error in $T_{M A C H}$}

We use the method of error propagation analysis (Taylor, 1982) on Eq. (9) which leads to the estimated Mach temperature error, $\Delta T$, being given by,

$$
\Delta T= \pm \frac{T_{0}}{A_{0}^{2}} \frac{2 V_{A}}{M^{2}} \sqrt{\left(\Delta V_{A}^{2}+\frac{V_{A}^{2}}{M^{2}} \Delta M^{2}\right)},
$$

where $\Delta V_{A}$ is the true-airspeed precision and $\Delta M$ is the Mach number precision. These precisions may be represented as the instrument's scale division, data increment or the standard deviation obtained from a sequence of measurements (Taylor, 1982). For Mode-S EHS reports the data increment for true-airspeed is 2 knots $\left(1.03 \mathrm{~ms}^{-1}\right)$ and for Mach number it is 0.004 (International Civil Aviation Organisation, 2012). We use in situ measurements of temperature and an error model for Mode-S EHS processing to validate estimates of temperature error given by Eq. (16), and suggest the source of the observed error estimates.

The true-airspeed and Mach number from flight B787 are used to generate the corresponding emulated Mode$\mathrm{S}$ EHS reports. In figure 4, profile (a) shows the estimated $\Delta T$ when the precision of the Mode-S EHS reported true-airspeed is taken to be $\Delta V_{A}=0.5 \times 2$ knots and Mach number is taken to be $\Delta M=0.5 \times 0.004$. It is clear that the magnitude of the estimated error increases from $2.0 \mathrm{~K}$ to $4.5 \mathrm{~K}$ as the aircraft's altitude decreases. Profile (a) assumes a fixed error value $\left(\Delta V_{A}, \Delta M\right)$ for each report of true-airspeed and Mach number so the estimated temperature error $(\Delta T)$ represents a maximum value. However, due to the binary representation of the data, there is a contribution to the error which arises from the process of rounding and truncation called the quantisation error (Widrow et al., 1996). It can be shown that when an analogue signal is digitized the quantization error is uniformly distributed between $\pm 0.5 \epsilon$, where $\epsilon$ is the magnitude of the data increment. The quantization error has a mean of zero and a standard deviation given by (Widrow et al., 1996),

$$
\sigma=\frac{\epsilon}{2 \sqrt{3}} .
$$

If we use the standard deviation given by Eq. (17) as a measure of precision due to quantisation (Taylor, 1982, Chapter 5) then for the true-airspeed, $\Delta V_{A}=2 / \sqrt{12}$ knots and for the Mach number, $\Delta M=0.004 / \sqrt{12}$. Figure 4 profile (b) shows that the magnitude of the estimated error due to quantisation is approximately half that shown in profile (a), and increases from $1.25 \mathrm{~K}$ to $2.5 \mathrm{~K}$ as the aircraft's altitude decreases. A sensitivity analysis on the magnitude and standard deviation due to quantisation error was performed to seek desirable values for data increments for Mach number and true-airspeed. This was done by increasing the number of binary bits for the Mode-S EHS reports of Mach number and true-airspeed.

The sensitivity analysis indicates that to achieve $\Delta T$ at around $1 \mathrm{~K}$ near the surface, shown in figure 4 profile (c), then we require that the true-airspeed precision to be $\Delta V_{A}=1 / \sqrt{12}$ knots and the Mach number precision to be $\Delta M=0.001 / \sqrt{12}$. However, it should be noted that the uncertainty profiles given in figure 4 are due to effects of quantisation error and do not consider other sources of error (Painting, 2003).

We use the quantisation error model for the precision (Eq. (17)) to analyse and characterize the error in $T_{M A C H}$ (given by Eq. (16)) when compared with $T_{R E F}$.

Figure 5 depicts box-average statistics for temperature differences $T_{M A C H}-T_{R E F}$. The data are binned into pressure altitude intervals of height $0.3 \mathrm{~km}$. Figure 5 (a) is the number of reports per altitude bin, $N_{b}$, expressed using a $\log _{10}$ scale. Figure 5 (b) depicts the vertical profile of the MB (squares) and RMSE (circles) for each pressure altitude bin. The box-average MB ranges between $-1 \mathrm{~K}$ and $1 \mathrm{~K}$ but is close to zero. This is expected since the difference $T_{M A C H}-T_{R E F}$ should on average be close to zero (compare with figure 3(c)). The box-average RMSE is greatest near the surface and decreases with altitude, with a total range of $1.2-2.5$ $\mathrm{K}$. (For comparison, for the whole flight the MB is $0.25 \mathrm{~K}$ and the RMSE is $2.06 \mathrm{~K}$.) Figure 5 (c) depicts the vertical profile of the box-average $\Delta T$ (diamonds), computed using Eq. (16) with precisions given by Eq. (17) where for true-airspeed $\epsilon=2$ knots and for Mach number $\epsilon=0.004$. Also depicted is the vertical profile of the box-average standard deviation (triangles) computed using Eq. (12), with the uncertainty estimated using Eq. (15). Apart from a few outliers, the trend of the box-average standard deviation appears to correspond well with the box-average $\Delta T$ profile. These results suggest that quantisation error in the Mach number and airspeed makes a significant contribution to the error in $T_{M A C H}$, which is the effect of Mode-S EHS processing. Figure 5 (d) depicts the results from (c) plotted against the box-average Mode-S EHS Mach number, since an aircraft in flight is controlled by reference to its Mach number. The reported Mach number is computed under the prevailing atmospheric pressure conditions (Eq. (2)) whereas the reported pressure altitude is referenced to a static mean-sea-level pressure under ISA conditions. Thus this may afford a more suitable representation for data assimilation of Mach Temperature. This result still suggests that there is a significant contribution to the error in $T_{M A C H}$ due to quantisation error. 


\subsection{Quality of Derived Horizontal-Wind Vector}

Figure 6 depicts the vertical profile of the wind components: fig 6(a) zonal $U_{R E F}$ and fig 6(c) meridional $V_{R E F}$ obtained from the FAAM's turbulence probe, while fig 6(b) zonal $U_{M o d e-S}$ and fig 6(d) meridional $V_{\text {Mode-S }}$ are the wind components obtained from applying the wind vector equations (10) and (11). The vertical striping effect in figures 6(b) and (d) may be due to the reduced precision of the Mode-S EHS reports of true-airspeed, magnetic-heading, ground-speed and ground-heading. The striping effect is more pronounced in the zonal wind component possibly because the flight trajectory and wind direction are mostly in this direction, so this may indicate a combined effect of the reduced precision of the true-airspeed, true-heading, ground-speed and groundheading brought about by the Mode-S EHS processing. To assess the effect of Mode-S EHS processing it is useful to compare the output Mode-S EHS data with the input ARINC data. This affords insight into partitioning errors that can be attributed to data processing and to other sources of error for the wind components.

In figure 7, the zonal $U_{A R I N C}$ and meridional $V_{A R I N C}$ wind components are obtained using data with ARINC precision and are compared with the reference observations. To facilitate plotting and for ease of comparison, outliers greater than $3 \sigma$ from $\mu$ were removed from the plots but were not removed from the computation of the results, see table 8 for details.

Figure 7 (a) depicts the vertical profile difference $U_{A R I N C}-U_{R E F}$ and figure $7(\mathrm{~d})$ depicts the vertical profile difference $V_{A R I N C}-V_{R E F}$. The trajectory for this flight was mostly East-West with a more North-South trajectory being at the start of the flight. The differences appear to occupy four zones. In figure 7 (a) between the altitude ranges $0 \mathrm{~m}$ to $1 \mathrm{~km}$ and $3 \mathrm{~km}$ to $6 \mathrm{~km}$ the difference is positive while between $1 \mathrm{~km}$ to $3 \mathrm{~km}$ and above $6 \mathrm{~km}$ the difference is negative. Similar differences are seen in figure $7(\mathrm{~d})$. In both plots the magnitude of the difference is of the order $\pm 1 \mathrm{~ms}^{-1}$. There appears also to be a directional bias which affects both wind components in the same way. Recall that the reference winds and ARINC precision winds are computed using different input data (except for the ground vector), and different calculation methods (see sections 3.4 and 4). A key difference appears to be the aircraft's heading. Directional errors relating to an aircraft's navigation are suggested by Drue et al. (2008), de Haan (2011) and Jacobs et al. (2014).

Figure $7(\mathrm{~b})$ depicts the difference $U_{M o d e-S}-U_{A R I N C}$ and figure $7(\mathrm{e})$ depicts the difference $V_{M o d e-S}$ $V_{A R I N C}$. Thus these figures show the effect of Mode-S EHS processing. For the zonal wind the differences are typically within $\pm 1 \mathrm{~ms}^{-1}$ and for the meridional wind the differences are typically within $\pm 0.5 \mathrm{~ms}^{-1}$. Factors that may explain why the magnitude of the meridional wind differences are smaller when compared to the zonal wind differences are: a strong zonal component to the wind direction when compared with the meridional component (figures 6(a) and (c)); this particular flight was mostly in the zonal direction. The wind differences appear evenly distributed when compared figures $7(\mathrm{a})$ and (d) respectively, this suggests that there is no directional bias due to Mode-S EHS processing. This is expected since the output Mode-S EHS data are just the input ARINC data rounded then truncated. Figure 7 (c) depicts the difference $U_{M o d e-S}-U_{R E F}$. It is clear from this plot that the magnitude of the differences is of the same order as that shown in figures 7(b). Also, two effects can be separated, firstly the directional bias seen in figure 7(a) is replicated and secondly the spread of the data seen figure 7(b) is superimposed. Similar results are seen for $V_{M o d e-S}-V_{R E F}$ in figure $7(\mathrm{f})$. However, these results do not make it clear as to the source of the directional bias, that is whether this is solely due to the heading reference system that provides the true-heading, contamination affecting the turbulence probe's pressure ports, e.g., ice particles, or some combination of the two. There is no record in the post flight report regarding contamination of the pressure ports.

These results indicate that error arising from Mode-S EHS processing make a significant contribution to the total observational error. In the next section an error model is used to account for some of the observed differences, and is also used to characterize the differences due to Mode-S EHS processing.

\subsection{Estimated Error in the Derived Horizontal-Wind Vector}

Following the method of analysis used for the Mach temperature error (section 5.3.2), we apply the propagationof-error method (Taylor, 1982) to equations (10) and (11), and we obtain an error equation for the zonal and meridional wind components,

$$
\begin{aligned}
\Delta U^{2}= & \left(\sin \left(\theta_{G}\right) \Delta V_{G}\right)^{2}+\left(V_{G} \cos \left(\theta_{G}\right) \Delta \theta_{G}\right)^{2}+ \\
& \left(-\sin \left(\theta_{A}\right) \Delta V_{A}\right)^{2}+\left(-V_{A} \cos \left(\theta_{A}\right) \Delta \theta_{A}\right)^{2}
\end{aligned}
$$

and

$$
\begin{aligned}
\Delta V^{2}= & \left(\cos \left(\theta_{G}\right) \Delta V_{G}\right)^{2}+\left(-V_{G} \sin \left(\theta_{G}\right) \Delta \theta_{G}\right)^{2}+ \\
& \left(-\cos \left(\theta_{A}\right) \Delta V_{A}\right)^{2}+\left(V_{A} \sin \left(\theta_{A}\right) \Delta \theta_{A}\right)^{2},
\end{aligned}
$$

where $\Delta V_{G}$ and $\Delta V_{A}$ are the precision errors in the ground-speed and true-airspeed in $\mathrm{ms}^{-1}$; and $\Delta \theta_{G}$ and $\Delta \theta_{A}$ are the precision errors in the ground-heading and true-heading respectively in radians. We have chosen to 
carry out the error analysis in the frame of reference of the earth, since the zonal and meridional wind are the variables used in the observation operator for aircraft winds in the UK Met Office assimilation system. However, an alternative, complementary, approach would be to carry out the analysis in the frame of the aircraft, and consider along-track and transverse components of the wind errors. This approach would result in a rotated form of equations (18) and (19).

We use the wind components error model (18),(19), to characterize the error in the zonal and meridional wind for the case study flight B787. For this flight calm conditions prevailed such that true-heading $\approx$ groundheading and true-airspeed $\approx$ ground-speed. We use the data increments of $\epsilon=2$ knots for the ground-speed and for true-airspeed and a data increment of $\epsilon=0.175^{\circ}$ for the ground-heading and true-heading, respectively (table 3). These data increments are used to compute precisions for the quantisation error given by Eq. (17).

It can be seen from equations (18) and (19) that the component wind error depends on three factors: the precision of the parameter, the directions and the speeds. For this case study flight, we consider each of these factors in turn.

1. Dependency on precisions: The main contributors to the wind component errors are the precisions of the true-airspeed and ground-speed. The magnitude of the precision due to quantisation error for airspeeds is $0.297 \mathrm{~ms}^{-1}$ and for the directions is 0.000882 radians (or equivalently $0.05^{\circ}$ ). The contribution from the precision in direction is airspeed dependent. In figure $8(\mathrm{a})$ the flight direction in the region labelled (v) changes from North $\left(0^{\circ}\right)$ to North-West $\left(315^{\circ}\right)$. This has the effect of increasing the zonal wind error as the contribution due to precision of speeds is increased. At the same time, the meridional wind error decreases with respect to the precision in speed, 8(b). The contribution due to the precision in direction remains small, particularly at low altitudes where airspeeds are lower.

2. Dependency on directions: When the aircraft headings are near the cardinal compass points $90^{\circ}$ or $270^{\circ}$ then the main contribution to the zonal wind error, $\Delta U$, is mostly due to the precision in the speeds. In figure $8(\mathrm{a})$, the region labelled (ii) the aircraft true heading is due West while for regions labelled (i) and (iii) it is due East. For these flight directions, 8(a) depicts the magnitude of the estimated error for the zonal wind component which is constant with altitude $\left(0.40 \mathrm{~ms}^{-1}\right)$. By contrast the contribution to the meridional wind error, $\Delta V$, is smaller, shown in figure $8(\mathrm{~b})$. We expect to see periodic variations in the magnitude of the wind component error. Thus when the aircraft headings are near the cardinal compass points $0^{\circ}$ and $180^{\circ}$ we observe the reverse case. Figure $8(\mathrm{~b})$, when the the aircraft true heading is due North (region labelled (iv)) the meridional wind component is constant with altitude $\left(0.40 \mathrm{~ms}^{-1}\right)$ and the corresponding zonal wind component error is smaller, as shown in figure 8(a) region (iv). These results are consistent with de Haan (2013a) who found airspeed corrections were most effective on the component of the wind parallel to the air vector, and heading corrections most effective on the transversal wind component.

3. Dependency on speeds: As noted earlier there is the contribution to the error due to the precision in the headings which in general is small but in equations (18) and (19) there are cross terms in speed and direction. We can see that the contribution to the error due to the precision of the headings depends also on the magnitude of the airspeed. When the speeds reach the order of $100 \mathrm{~ms}^{-1}$ or more then the error due to the precision in direction becomes significant $(100 \times 0.000882)$, particularly at the cardinal compass points where the periodic terms are at a maximum. The airspeed varies on altitude, with speeds of $50 \mathrm{~ms}^{-1}$ near the surface and $250 \mathrm{~ms}^{-1}$ at $10 \mathrm{~km}$. Since airspeed increases with altitude so does the contribution to the zonal and meridional wind errors due to the precision in direction. An example of this error is shown in figure 8(b). For regions (i), (ii) and (iii) we see the main contribution to the meridional error is from the precision in direction which is airspeed dependent.

Under the calm conditions of this flight the magnitude of the estimated error in zonal and meridional wind components, due to quantisation errors in the speeds and directions, varies periodically between $0.15 \mathrm{~ms}^{-1}$ and $0.40 \mathrm{~ms}^{-1}$. However, we have no data for these estimated errors in wind conditions with a higher range of wind speeds.

For the wind components in this case study we use the same analysis method as used for the mean temperature profiles in section 5.3.1. The wind component profiles are depicted in figures 9 and 10 . The MB are depicted as squares, the RMSE as circles, the diamonds are the box-average of the estimated wind component error due to quantisation, and the triangles are the box-average standard deviation from applying Eq. (12). The uncertainty in the standard deviation is calculated using Eq. (15). The number of reports used to compute the box average are depicted as log plots adjacent to each plot. We first consider the effect of Mode-S EHS processing then compare the Mode-S EHS processed results with in situ observations.

Figure 9 depicts the effect of Mode-S EHS processing on the box-average standard deviation. Figures 9 (a) and (c) shows that the MB is near zero for the zonal and meridional wind direction. The deviations from zero $\mathrm{MB}$ are possibly due to sampling not being representative leading to positive and negative biases. These data 
are at one second intervals. The side bar in the figure gives an indication of the number of records available for each altitude bin. There are two regions $(7 \mathrm{~km}$ and $10 \mathrm{~km})$ where the number of data points is less than 30 . For the remaining non-level flights regions the number of data points range between 45 and 111 data points; level flight regions contain $1000+$ data points. Some of the occurrences of a non-zero bias also arise when the Mode-S EHS rounding results in a greater difference in one or other of the input data components. For example, when the differences between the input and output ground-speeds are greater than the corresponding input and output for the true-airspeed. This occurs for the lowest data point in figure 9 (a) at $150 \mathrm{~m}$. These differences that arise from the Mode-S EHS processing are reflected in the RMSE. Figures 9 (b) and (d) depicts the observed sample standard deviation (triangles) for each altitude bin obtained by applying Eq. (12). The uncertainty for the standard deviation is given by Eq. (15). The estimated wind component errors (diamonds) are given by equations (18) and (19). These assume that the precision of the input data are represented by the standard deviation due to quantisation error given by Eq. (17). There is good correspondence between the box-averaged observed and expected standard deviations, although there is a small amount of variability. In figures 9 (b) and (d) a single point stands out at $5.7 \mathrm{~km}$. For the zonal wind the standard deviation is 0.21 $\mathrm{ms}^{-1}$ whereas for the meridional wind the standard deviation is $0.45 \mathrm{~ms}^{-1}$ these are consistent with expected standard deviations (shown in figure 8). Examination of the time-series data for these data points indicate that the aircraft was heading North. The apparent rapid change in the magnitude of the standard deviation is artificial: it occurs due to quality control procedures removing an aircraft manoeuvre. Just below the $5.7 \mathrm{~km}$ level the aircraft trajectory is West-East whilst just above the $5.7 \mathrm{~km}$ level the trajectory is East-West. Figure 9 (e) depicts the number of reports per altitude bin, $N_{b}$, expressed using a $\log _{10}$ scale. This distribution is the same for each wind component.

Figure 10 compares the Mode-S EHS processed derived zonal and meridional wind components with corresponding in situ reference observations. In figures 10 (a) and (c) the MB ranges between $-1.00 \mathrm{~ms}^{-1} \mathrm{and}^{+1.00}$ $\mathrm{ms}^{-1}$. It is notable that between the altitudes $3 \mathrm{~km}$ to $6 \mathrm{~km}$ the bias is positive whilst the aircraft trajectory is West-East. Above and below these altitudes the bias is negative whilst the aircraft trajectory is East-West. We suggest that this change in the wind bias may be due to a bias in the heading reference system, although a bias in the turbulence probe measurements cannot be ruled out. This bias pattern does not appear to affect the Mode-S EHS processing (figure 9). The RMSE varies between $0.50 \mathrm{~ms}^{-1}$ to $0.80 \mathrm{~ms}^{-1}$, with a significant increase to $1.30 \mathrm{~ms}^{-1}$ above $6 \mathrm{~km}$ which appears to coincide with an increase in the magnitude of the MB. Figures 10 (b) and (d) depicts the box-average standard deviation (triangles) and the box-averaged expected error (diamonds). There is less correspondence between the box-averaged observed and expected standard deviations. We observe that some fraction of the quantisation error still persists. The periodic behaviour of the standard deviation is illustrated by the two points at $5.7 \mathrm{~km}$ (as mentioned above). There is more variation especially at the lower altitudes, which may be related to a directional bias. It is difficult to isolate the directional error since there is no reference data that can be used to quantify the directional error in the aircraft's heading reference system. There may be fine-scale variability being recorded by the turbulence probe, which is more sensitive to such variations. Furthermore, the fine-scale variability would be too transient to affect the aircraft's inertia. Figure 10 (e) depicts the number of reports per altitude bin, $N_{b}$, expressed using a $\log _{10}$ scale. This distribution is the same for each wind component.

These differences aside, the results depicted in figures 9 and 10 suggest that quantisation error in the aircraft's headings and speeds contributes to the total error in the computed Mode-S EHS wind components.

\section{Results obtained for all cases}

In this section the error equations for temperature and horizontal wind components are applied to all cases listed in table 5 using the analysis steps described in section 5 . The precisions for the input data are taken to be the standard deviations for quantisation error given by Eq. (17) expressed in SI units. So $\Delta M=(0.004 / \sqrt{12})$, $\Delta V_{A}=\Delta V_{G}=(1.03 / \sqrt{12}) \mathrm{ms}^{-1}$ and $\Delta \theta_{A}=\Delta \theta_{G}=(0.00305 / \sqrt{12})$ radians (or equivalently $0.05^{\circ}$ ). The vertical profiles of the box-averaged estimated errors are compared with the box-averaged standard deviation obtained from the MB and RMSE. We first present the results for the estimated temperature error then the results for the estimated error in the horizontal wind components.

Figure 11 depicts the vertical profile for the box-averages of the Mode-S EHS derived temperatures. Figure 11 (a) is the number of reports per altitude bin, $N_{b}$, expressed using a $\log _{10}$ scale. Figure 11 (b) shows that the overall $\mathrm{MB}$ is near zero, there is less variability in these results when compared with figure 5 which may be directionally dependent. The RMSE varies from $2.5 \mathrm{~K}$ near the surface decreasing smoothly with altitude to $1.25 \mathrm{~K}$ at $10 \mathrm{~km}$. Figure 11 (c) shows the observed standard deviation (triangles) correlates well with the estimated Mach temperature error using the error model given by Eq. (16) (similar to profile (b) in figure 4). Figure 11 (d) expresses the standard deviation results against Mode-S EHS Mach number, which may be a more useful representation for data assimilation, and which also shows good agreement between standard deviations from the observed and quantisation errors. We conclude from this analysis that the estimated error 
in the derived Mode-S EHS temperature can be represented by standard deviation of quantisation error for $M$ and $V_{A}$ that results from Mode-S EHS processing. This estimated error does not include other sources of error such as the instrument error. For this result to be valid we require that the magnitude of the instrument error is smaller than the standard deviation of quantisation error.

Figure 12 depicts the effect of Mode-S EHS processing for the zonal and meridional wind components. The vertical profiles are for the box-averaged MB (squares) and RMSE (circles), figures 12 (a) and (c). For the Mode-S EHS processing the MB is near zero for both the zonal and meridional wind below $4 \mathrm{~km}$ altitude. Above $4 \mathrm{~km}$ the zonal wind bias varies between $-1.8 \mathrm{~ms}^{-1}$ and $1.2 \mathrm{~ms}^{-1}$. This variation may be due to the non-uniform sampling distribution above this level when compared to those below this level. Examination of the distribution of differences between the aircraft state vector at ARINC precision (before processing) and Mode-S EHS precision (after processing) shows that these are mostly uniform below $4 \mathrm{~km}$ and non-uniform above. The difference in variability between the zonal and meridional components may be due to flight trajectories being mostly East-West above $4 \mathrm{~km}$, indicating a directional bias. The increase in the RMSE for the zonal wind may also be due to the non-uniform sampling distribution. Similar conclusions may be drawn for the meridional wind. The MB and RMSE are used to compute the box-average $\sigma$, depicted as the (triangles) in figures $12(\mathrm{~b})$ and $12(\mathrm{~d})$. The vertical profile of $\sigma$ shows good agreement with the estimated error (diamonds), given by equations (18) and (19), when precisions for speeds and directions are represented as the standard deviation due to quantisation. The minima in the estimated zonal wind $\sigma$ at $4 \mathrm{~km}$ and $6 \mathrm{~km}$ of $0.25 \mathrm{~ms}^{-1}$ and $0.30 \mathrm{~ms}^{-1}$, and the corresponding maxima in the meridional wind of $0.35 \mathrm{~ms}^{-1}$ and $0.30 \mathrm{~ms}^{-1}$ are most likely to be due to the aircraft's trajectory changing direction. This behaviour is suggested by figure 8 , as discussed in section 5.4 . Figure 12 (e) depicts the number of reports per altitude bin, $N_{b}$, expressed using a $\log _{10}$ scale. This distribution is the same for each wind component.

Figure 13 compares the Mode-S EHS processed derived zonal and meridional wind components with corresponding in situ reference observations. In figures 13 (a) and (c) the MB below $4 \mathrm{~km}$ is near zero. Above this level, for the zonal wind the MB ranges between $-1.4 \mathrm{~ms}^{-1}$ to $2.0 \mathrm{~ms}^{-1}$ while for the meridional wind the MB ranges from $0.25 \mathrm{~ms}^{-1}$ to $-1.0 \mathrm{~ms}^{-1}$. This variability is thought to be related to a directional bias. Figures 13 (b) and (d) depicts the box-average standard deviation (triangles) and the box-averaged expected error (diamonds). It is clear that there is less correspondence between the observed standard deviation with respect to the measured wind components and the expected error due Mode-S EHS processing. This suggests that there are additional sources of error, such as instrument error, or fine-scale variability being recorded by the turbulence probe (which is more sensitive to such variations) and which are too transient to affect the aircraft's inertia. Figure 13 (e) depicts the number of reports per altitude bin, $N_{b}$, expressed using a $\log _{10}$ scale. This distribution is the same for each wind component.

We conclude that from this analysis that the estimated error in the derived Mode-S EHS horizontal wind includes a component that can be represented by the standard deviation of quantisation error that results from Mode-S EHS processing. The majority of the case studies involved trajectories that were mainly East-West in direction. Therefore the case studies do not provide a uniform distribution of headings and wind-vector. Figure 14(a) depicts the distribution of differences for the zonal $\left(U_{M o d e-S}-U_{R E F}\right)$ and figure $14(\mathrm{~b})$ meridional $\left(V_{M o d e-S}-V_{R E F}\right)$ wind components. The range of differences are shown in grey while the MB is shown by the black circles. The MB is computed over bin-widths of $5^{\circ}$ intervals. Figure 14 (c) depicts the distribution of the number of records used to compute the MB expressed as a log plot. This shows that the sampling is not uniform in direction. For uniform distribution we would expect the MB for the wind component difference to be near zero. However, figures 14 (a) and (b) show that there is a directionally-based bias. It is not clear where the systematic error arises, whether it is due to the heading reference system (Drue et al., 2008; de Haan, 2011; Jacobs et al., 2014) or to an instrument sensor error or a combination of the two. It is known that the turbulence probe can become contaminated with aerosols and ice particles during the flight but there are no reports of such contamination for these case-study flights. Quantifying the directionally dependent error remains an area of active investigation.

\section{Summary and Conclusions}

This paper studies uncertainty in the derived observations obtained from Mode-S EHS, with a focus on errors due to reduced precision. The source of the research data is a research aircraft, BAe-146 FAAM, which has an atypical mode of operation when compared with commercial aircraft. For example, the flight trajectories tend to be short and within a limited area; the ascents and descents are steeper and may occur at any time during the flight; and the research aircraft sets out to operate in atmospheric conditions that commercial aircraft would ordinarily avoid or not encounter. Furthermore, the BAe-146 FAAM is not equipped with a Mode-S EHS transponder. Mode-S EHS data used for reporting the aircraft's state vector were emulated using avionics data recorded aboard the aircraft. The emulated Mode-S EHS reports were used to derive meteorological observations for temperature and horizontal wind components. The derived observations were compared with 
reference observations made in situ using research grade instruments. The effect of the Mode-S EHS processing is to reduce the precision of the aircraft's state vector from 16 binary-bits to 10 binary-bits. Error models were used to quantify the estimated error in the derived observations arising from Mode-S EHS processing. However, no account was taken of processing either by the flight management system or the transponder itself since these details were unavailable.

An error model was used to estimate the Mach temperature error, $\Delta T$. It was found that $\Delta T$ varies according to the magnitude of the precisions for true-airspeed and Mach number. When the precisions were represented using the standard deviation for quantisation error then $\Delta T$ varied from $2.5 \mathrm{~K}$ to $1.25 \mathrm{~K}$ for the pressure altitude range $0 \mathrm{~km}$ to $10 \mathrm{~km}$, with a near linear trend between the two points. However, this result excludes other sources of error, e.g., instrument error due to calibration drift, noise and response times, which are expected to be small when compared to the quantisation error. We note that there are likely to be temporal correlations in our data for observation errors. However, this is also the case for actual Mode-S EHS data sampled by secondary surveillance radar. Quantization errors are not white noise because of the rounding processes involved in reducing the precision. Heading errors also result in systematic errors. It is important to bear this in mind for data assimilation. Further work is required to quantify the effects of error correlations.

An error model was also used to estimate the error in the horizontal wind components. The precisions of the speeds and directions were represented using the standard deviation for quantisation error. It was found that the magnitude of the estimated error for zonal wind varied from $0.25 \mathrm{~ms}^{-1}$ to $0.40 \mathrm{~ms}^{-1}$, while the estimated error of the meridional wind was almost constant by altitude with a magnitude near $0.25 \mathrm{~ms}^{-1}$. However, these results are not fully representative for all aircraft flight directions. It was also suggested that the differences in the wind components may be affected by a systematic error that is directionally dependent. The magnitude of the errors are smaller than those obtained in previous studies since we were investigating the precision error and not looking for a true estimate of the actual error inherent in the FAAM data itself.

Quantifying the statistical error due to Mode-S EHS processing may assist with data-assimilation of the derived observations. For example, the total observational error may be partitioned between the variability due to the aircraft's trajectory, its instruments, processing algorithms and the atmosphere. When suitable correction schemes are used, the derived horizontal wind and temperatures (above a certain height) have already been shown to be useful in data assimilation for regional numerical weather prediction (de Haan and Stoffelen, 2012; de Haan, 2013b; Strajnar et al., 2015; Lange and Janjic, 2015). Similarly, Mach temperature reports may offer further useful information in the boundary layer when aggregated from multiple aircraft.

\section{Acknowledgments}

The authors gratefully acknowledge the following people and organizations who provided either technical assistance, guidance and/or financial support for this project: The United Kingdom Civil Aviation Authority for financial support at the start of the project. The Met Office for financial support for the continuation of the project. Airborne data was obtained using the BAe-146-301 Atmospheric Research Aircraft flown by Directflight Ltd. The research instruments are managed and maintained by the Facility for Airborne Atmospheric Measurements (FAAM), which is a joint entity of the United Kingdom's Natural Environment Research Council and the Met Office. Axel Wellpott, FAAM team, for providing technical details and documentation for the BAe-146 aircraft instruments. Phil Brown, Met Office, for his insights into the operation of the FAAM science instruments. Helen Wells, Met Office, for her review and comments of the draft paper. Professor David Stevenson, University of Exeter, for his insights into statistical methods for analysing observations data. FAAM data used in this paper are available for academic purposes from the Centre for Environmental Data Analysis (http://www.ceda.ac.uk/). Access to data that is not in the public domain maybe subject to restrictions or to license conditions. Software used to generate the results presented in this paper is available on request to the corresponding author, and is subject to license conditions.

\section{References}

Airlines Electronic Engineering Committee (2004), Mark 33 Digital Information Transfer System (DITS) Part 1. Functional description, electrical interface, label assignments and word formats arinc specification 429 part 1-17, Tech. rep.

Applanix (2006), POS AV v5 installation and operation guide, Tech. rep., Applanix Corporation.

Ballard, S. P., Z. Li, D. Simonin, and J-F. Caron. (2015), Performance of 4D-VAR NWP-based nowcasting of precipitation at the Met Office for summer 2012, Quarterly Journal of the Royal Meteorological Society, doi:10.1002/qj.2665.

Ballish, B. A., and V. K. Kumar (2008), Systematic differences in aircraft and radiosonde temperatures im- 
plications for nwp and climate studies, Bulletin of the American Meteorological Society, pp. 1689-1707, doi: 10.1175/2008BAMS2332.1.

Begueret, J. B., A. Mariano, and D. Dallet (2008), High-speed a/d; d/a conversion: A survey, in Bipolar/BiCMOS Circuits and Technology Meeting, 2008. BCTM 2008. IEEE, pp. 260-264, doi:10.1109/BIPOL. 2008.4662757.

Benjamin, S. G., and B. E. Schwartz (1999), Accuracy of ACARS wind and temperature observations determined by collocation, Weather and Forecasting, 14, 1032 - 1038.

Boisvert, R. E., and V. A. Orlando (1993), ADS-Mode-S system overview, IEEE.

Brown, P. R. A. (2004), Turbulence probe: Flow angle and tas calibration, Tech. rep., Facility for Airborne Atmospheric Measurements.

Cardinali, C., L. Isaksen, and E. Andersson (2003), Use and impact of automated aircraft data in a global 4D-VAR data assimilation system, Monthly Weather Review, 131, 1865-1877.

Civil Aviation Authority (2013), CAP 562 civil aircraft airworthiness information and procedures, chapter 34, navigation leaflet 34-10 compass base surveying and leaflet 34-20 compasses, Tech. rep., Safety and Airspace Regulation Group, Civil Aviation Authority, United Kingdom.

Collinson, R. P. G. (2011), Introduction to Avionics Systems, third edition ed., Springer.

Daley, R. (1991), Atmospheric Data Analysis, Cambridge Atmospheric and Space Science Series, Cambridge University Press.

Dance, S. L. (2004), Issues in high resolution limited area data assimilation for quantitative precipitation forecasting, Physica D: Nonlinear Phenomena, 196(12), 1 - 27, doi:10.1016/j.physd.2004.05.001.

de Haan, S. (2010), Quality assessment of high resolution wind and temperature observation from Mode-S KNMI Scientific Report, WR2009-07 (rev.), KNMI, De Bilt, The Netherlands.

de Haan, S. (2011), High-resolution wind and temperature observations from aircraft tracked by Mode-S air traffic control radar, Journal of Geophysical Research: Atmospheres, 116(D10), doi:10.1029/2010JD015264.

de Haan, S. and A. Stoffelen (2012), Assimilation of high-resolution Mode-S wind and temperature observations in a regional NWP Model for nowcasting applications. Wea. Forecasting, 27, 918-937.

de Haan, S. (2013a), An improved correction method for high quality wind and temperature observations derived from Mode-S EHS KNMI Technical Report, TR-388, KNMI, De Bilt, The Netherlands.

de Haan, S., (2013b) Mode-S Enhanced Surveillance derived observations from multiple air traffic control radars and the impact in hourly HIRLAM, ALADIN -HIRLAM Newsletter 1, 4-8

de Haan, S., (2015) Estimates of Mode-S EHS aircraft derived wind observation errors using triple collocation Atmos. Meas. Tech. Discuss., 8, 12633-12661,

de Leege, A. M. P., M. M. Van Paassen, and M. Mulder (2012), Using automatic dependent surveillancebroadcast for meteorological monitoring, Journal of Aircraft, 50(1), 249-261.

Drue, C., W. Frey, A. Hoff, and T. Hauf (2008), Aircraft type-specific errors in AMDAR weather reports form commercial aircraft, Quarterly Journal of the Royal Meteorological Society, 134, 229-239.

Drue, C., T. Hauf, and A. Hoff (2010), Comparison of boundary-layer profiles and layer detection by AMDAR and WTR/RASS at Frankfurt airport, Boundary-Layer Meteorology, 135(3), 407-432, doi:10.1007/ s10546-010-9485-0.

Eden, P. (2013a), Monthly weather log: June 2013, Weather, 68(8), i-iv, doi:10.1002/wea.2022.

Eden, P. (2013b), Monthly weather log: July 2013, Weather, 68(9), i-iv, doi:10.1002/wea.2025.

European Organisation for Civil Aviation Equipment (2008), Minimum operational performance specification for secondary surveillance radar Mode-S transponders: Document ED-73c, Tech. rep., The European Organisation for Civil Aviation Equipment.

Houghton, E., and P. Carpenter (2003), Aerodynamics For Engineering Students, Elsevier Science.

International Civil Aviation Organisation (1993), Manual of the ICAO standard atmosphere: Extended to 80 kilometres (262 500 feet) third edition, Tech. Rep. Doc 7488-CD, International Civil Aviation Organisation.

International Civil Aviation Organisation (2010), Annex 10 to the convention on international civil aviation aeronautical telecommunications volume IV surveillance radar and collision avoidance systems ed 5, Tech. rep., International Civil Aviation Organisation.

International Civil Aviation Organisation (2012), Technical provisions for mode s services and extended squitter, Tech. Rep. Doc 9871, International Civil Aviation Organisation.

Jacobs, N. A., D. J. Mulally, and A. K. Anderson (2014), Correction of flux valve-based heading for improvement of aircraft wind observations, Journal of Atmospheric and Oceanic Technology.

Jolliffe, I. T., and D. B. Stephenson (2012), Forecast Verification: A Practitioner's Guide In Atmospheric Science, John Wiley \& Sons.

Lange, H., and T. Janjic (2015) Assimilation of Mode-S EHS aircraft observations in COSMO-KENDA. Mon. Wea. Rev. doi:10.1175/MWR-D-15-0112.1 
Lawson, R. P., and W. A. Cooper (1990), Performance of some airborne thermometers in clouds, Journal of Atmospheric and Oceanic Technology, 7(3), 480-494.

Leon, D. C., J. R. French, S. Lasher-Trapp, A. M. Blyth, S. J. Abel, S. Ballard, A. Barrett, L. J. Bennett, K. Bower, B. Brooks, P. Brown, C. Charlton-Perez, T. Choularton, P. Clark, C. Collier, J. Crosier, Z. Cui, S. Dey, D. Dufton, C. Eagle, M. J. Flynn, M. Gallagher, C. Halliwell, K. Hanley, L. Hawkness-Smith, Y. Huang, G. Kelly, M. Kitchen, A. Korolev, H. Lean, Z. Liu, J. Marsham, D. Moser, J. Nicol, E. G. Norton, D. Plummer, J. Price, H. Ricketts, N. Roberts, P. D. Rosenberg, D. Simonin, J. W. Taylor, R. Warren, P. I. Williams, and G. Young (2015), The COnvective Precipitation Experiment (COPE): Investigating the origins of heavy precipitation in the southwestern UK, Bulletin of the American Meteorological Society, doi: 10.1175/BAMS-D-14-00157.1inpress.

Maus, S., S. Macmillan, S. McLean, B. Hamilton, A. Thomson, M. Nair, and C. Rollins (2010), The US/UK World Magnetic Model for 2010-2015, NOAA Technical Report NESDIS/NGDC, Tech. rep.

Montmerle, T. (2014), Statement of guidance for high resolution numerical weather prediction, Tech. rep., ETEGOS -7, World Meteorological Organisation.

Moyna, B., C. Lee, J. Charlton, I. Rule, R. King, O. M, and V. Kangas (2010), ISMAR: Towards a sub millimetre-wave airborne demonstrator for the observation of precipitation and ice clouds.

Mulally, D., and A. Anderson (2011), Correction of aircraft flux valve based heading for two-dimensional winds aloft calculations using weather model comparisons, in 15th Symposium on Integrated Observing and Assimilation Systems for Atmosphere, Oceans, and Land Surface (IOAS-AOLS).

Nakamura, D. (2013), Magnetic variation review and recommendations. Tech. rep., Performance based operations Aviation Rulemaking Committee, Federal Aviation Administration

Nicholls, S. (1980), The measurement of flight level wind and aircraft position by the MRF Hercules, Tech. rep., Meteorological Research Flight - Farnbourgh, Meteorological Office, United Kingdom, MRF Internal Note No. 9.

Painting, C. (2003), Aircraft Meteorological Data Relay (AMDAR) Reference Manual, World Meteorological Organisation, Secretariat of the World Meteorological Organization, Geneva, Switzerland, WMO No. 958 ed.

Rennie, S. J., S. L. Dance, A. J. Illingworth, S. P. Ballard, and D. Simonin (2011), 3D-VAR assimilation of insect-derived Doppler radar radial winds in convective cases using a high-resolution model, Monthly Weather Review, 139 (4), 1148-1163, doi:10.1175/2010MWR3482.1.

Ross, S. M. (2009), Introduction to Probability and Statistics for Engineers and Scientists (Fourth Edition), Academic Press, Boston.

Schwartz, B. E., and S. Benjamin (1995), A comparison of temperature and wind measurements from ACARSequipped aircraft and rawinsondes, Weather and Forecasting, 10, 528-544.

Simonin, D., S. P. Ballard, and Z. Li (2014), Doppler radar radial wind assimilation using an hourly cycling 3D-VAR with a $1.5 \mathrm{~km}$ resolution version of the Met Office Unified Model for nowcasting, Quarterly Journal of the Royal Meteorological Society, 140(684), 2298-2314, doi:10.1002/qj.2298.

Smith, M., and G. Gratton (2004), Facility for Airborne Atmospheric Measurements; Met Office; Natural Environment Research Council: Facility for airborne atmospheric measurements (FAAM) flights. NCAS British Atmospheric Data centre.

Society of Automotive Enginneers International (1996), AS8002, revision: A, air data computer - minimum performance standard, Tech. rep., Society of Automotive Enginneers International.

Spitzer, C. R. (2006), Avionics: Elements, Software and Functions, The Avionics Handbook, Second Edition, CRC Press.

Stickland, J., and A. T. F. Grooters (2005), The global AMDAR programme, International Symposium on Remote Sensing of the Environment, St. Petersburg, Russian Federation.

Stickney, T. M., M. W. Shedlov, and D. I. Thompson (1994), Goodrich total temperature sensors technical report 5755 revision c, 1994, Tech. rep., Rosemount Aerospace Inc.

Stone, E. K., and M. Kitchen (2015), Introducing an approach for extracting temperature from aircraft GNSS and pressure altitude reports in ADS-B messages, Journal of Atmospheric and Oceanic Technology, 32(4), 736-743, doi:10.1175/JTECH-D-14-00192.1.

Strajnar, B. (2012), Validation of Mode-S meteorological routine air report aircraft observations, Journal of Geophysical Research, 117, doi:10.1029/2012JD018315.

Strajnar, B., N. Zagar, and L. Berre (2015), Impact of new aircraft observations Mode-S MRAR in a mesoscale NWP Model, J. Geophys. Res. Atmos., 120, doi:10.1002/2014JD022654

Sun, J., M. Xue, J. W. Wilson, I. Zawadzki, S. P. Ballard, J. Onvlee-Hooimeyer, P. Joe, D. M. Barker, P. Li, B. Golding, M. Xu, and J. Pinto (2014), Use of NWP for nowcasting convective precipitation., Bulletin of the American Meteorological Society, pp. 409-426, doi:10.1175/BAMS-D-11-00263.1.

Taylor, J. R. (1982), An Introduction to Error Analysis - The Study of Uncertainties in Physical Measurements, 2nd ed., University Science Books, 55D Gate Five Road, Sausalito, CA 94965. 
Tjernstrãm, M., and C. A. Friehe (1991), Analysis of a radome air-motion system on a twin-jet aircraft for boundary-layer research, Journal of Atmospheric and Oceanic Technology, 8(1), 19-40, doi: 10.1175/1520-0426(1991)008<0019:AOARAM $\rangle 2.0 . C O ; 2$.

Waller, J. A., S. L. Dance, A. S. Lawless, N. K. Nichols, and J. R. Eyre (2014), Representativity error for temperature and humidity using the met office high-resolution models, Quarterly Journal of the Royal Meteorological Society, 140(681), 1189-1197, doi:10.1002/qj.2207.

Weinstein, B. (2009), Correcting the effects of magnetic variation, Boeing AERO Magazine.

Widrow, B., I. Kollar, and M. Liu (1996), Statistical theory of quantization, IEEE Transactions on Instrumentation and Measurement, 45(2), 353-361.

Wilks, D. S. (2011), Statistical methods in the atmospheric sciences 3rd edition, International Geophysics Series, vol. 100, Elsevier, Amsterdam.

Woodfield, A. A., and P. I. Hayne (1965), C.P. No. 809, Ministry Of Aviation Aeronautical Research Council, Measurement of Air Temperature on an Aircraft Travelling at High Subsonic and Supersonic Speeds, Her Majesty's Stationery Office, London.

Woolley, A. (2008a), GPS/Inertial navigation unit installation test report. FAAM core GPS-aided Inertial Navigation System, providing attitude, position and velocity data., Tech. rep., Facility for Airborne Atmospheric Measurements, http://www.faam.ac.uk/index.php/science-instruments/primary-systems/103-gin Last accessed 2015-10-14.

Woolley, A. (2008b), Rosemount temperature data, Tech. rep., Facility for Airborne Atmospheric Measurements.

Woolley, A. (2009), Temperature instrumentation - science requirments temperature working group report 2008, Tech. rep., Facility for Airborne Atmospheric Measurements.

Woolley, A. (2014a), Facility for Atmospheric Airborne Measurements - aircraft horizontal wind vectors, Tech. rep., Facility for Airborne Atmospheric Measurements.

Woolley, A. (2014b), FAAM primary systems, Tech. rep., Facility for Airborne Atmospheric Measurements. 


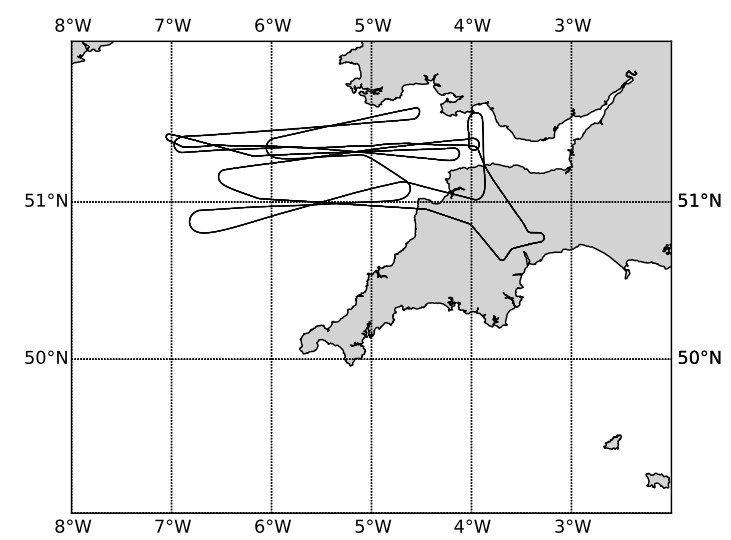

Figure 1: Horizontal projection of the flight trajectory for B787 (11th July 2013). The thin black line is the full flight trajectory. The grey shaded area is the South-west region of the United Kingdom. The flight started at 0900 UTC and ended at 1300 UTC.
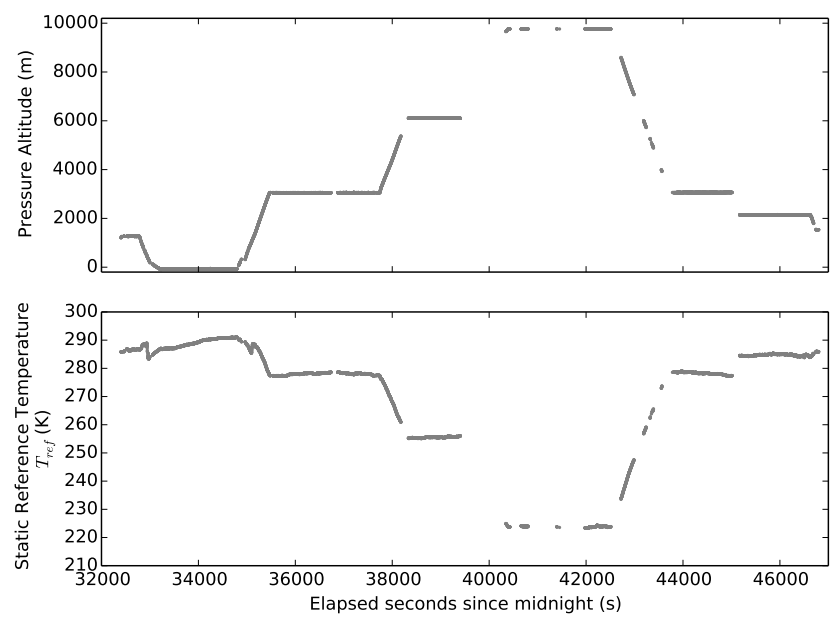

Figure 2: Flight B787 (11th July 2013) vertical profile of pressure altitude (top) and de-iced static reference temperature (bottom). Gaps in the profile indicate regions where data are removed following quality control processing. 

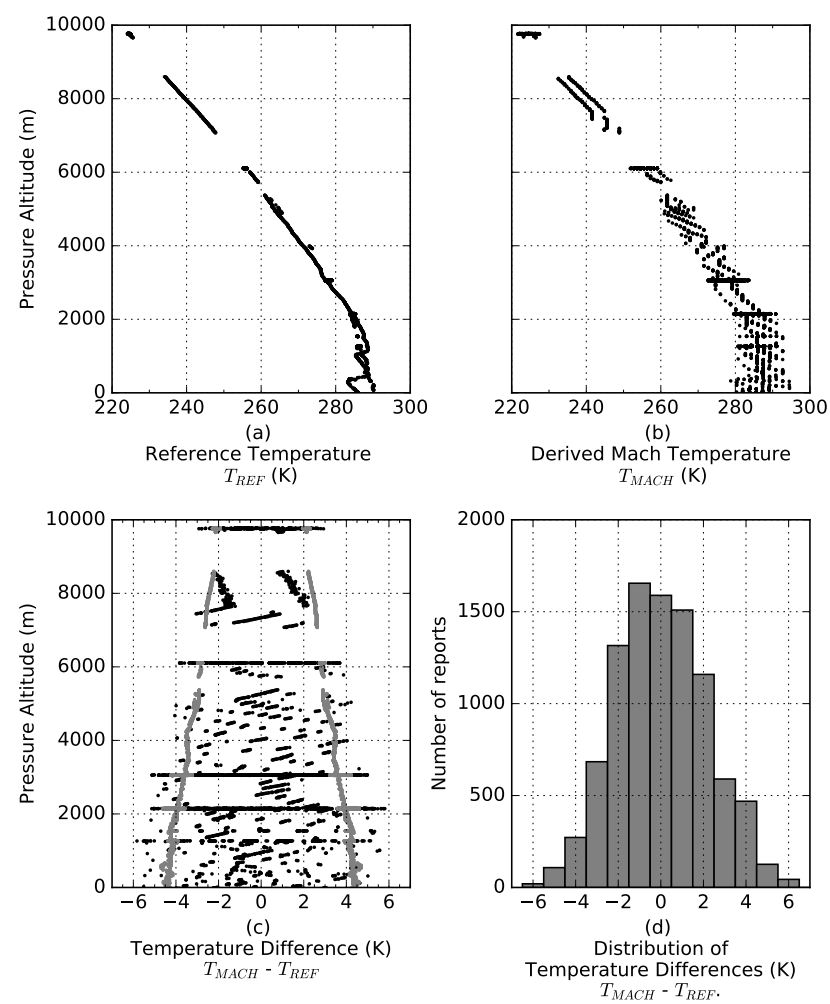

Figure 3: Flight B787 (11th July) (a) Vertical profile of reference temperature $T_{R E F}$. (b) Vertical profile of derived Mach temperature, $T_{M A C H}$. The stripe effect is the result of the reduced precision of the input data. (c) Vertical profile of temperature difference $T_{M A C H}-T_{R E F}$ (black). The estimated maximum error profile for Mach temperature (grey) (see also figure 4(a)). (d) Histogram of temperature differences using a centred bin width of $1 \mathrm{~K}$.

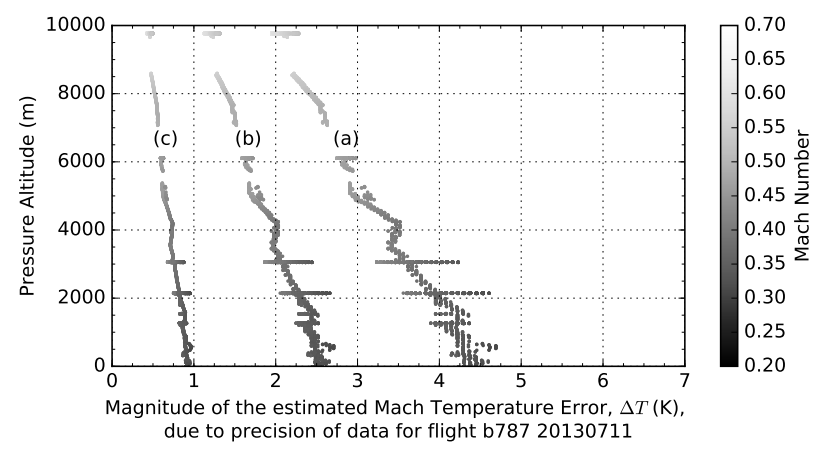

(a) Maximum Error, (b) Quantisation Error, (c) Ideal Quantisation Error.

Figure 4: This plot shows the vertical profile of the estimated error in the Mach temperature, $\Delta T$, (using Eq. (16)) derived from the emulated Mode-S EHS reports of true-airspeed and Mach number for flight B787 on 201307-11. Gaps in the vertical profile indicate where data were removed as a result of quality control processing. The striped effect, most visible in profile (a), is the result of numerical rounding and truncation required for Mode-S EHS reporting precisions. Profile (a) shows the variation of $\Delta T$ with pressure altitude assuming precisions of the reported true-airspeed is $\Delta V_{A}=1 \mathrm{knot}\left(0.51444 \mathrm{~ms}^{-1}\right)$ and Mach number is $\Delta M=0.002$. Profile (b) is the variation of $\Delta T$ assuming precisions arise from the standard deviation of quantisation error (using Eq. (17)), $\Delta V_{A}=2 / \sqrt{12}$ knots and $\Delta M=0.004 / \sqrt{12}$. Profile (c) is the result of a sensitivity analysis to achieve an estimated temperature error of $1 \mathrm{~K}$ near the surface assuming the precisions for standard deviation of quantisation error are $\Delta V_{A}=1 / \sqrt{12}$ knots and $\Delta M=0.001 / \sqrt{12}$. The colour of the line and side-bar indicates the Mach number range for when the BAe-146 is in flight. Number of reports $=9541$. 

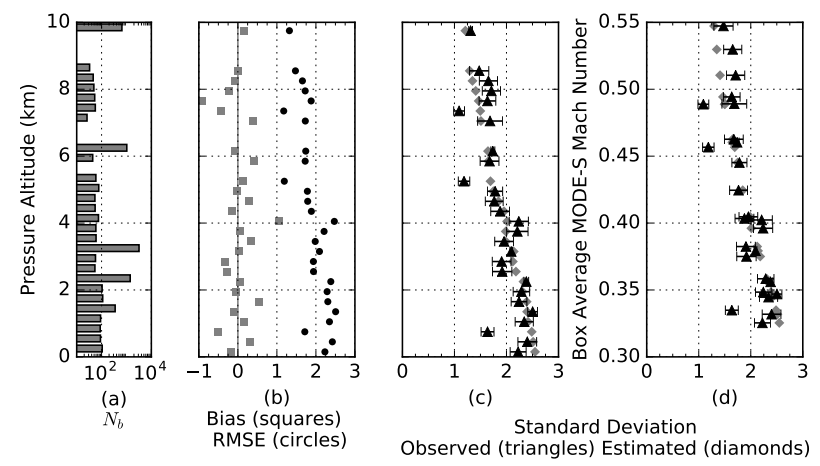

Figure 5: Flight B787 (11th July). Box average statistics for temperature. Results binned by altitude, with bin heights at $0.3 \mathrm{~km}$ intervals. Plot (a) is the number of reports per altitude bin, $N_{b}$, expressed using a $\log _{10}$ scale. Plot (b) vertical profile of temperature difference $\left(T_{M A C H}-T_{R E F}\right)$ mean bias (MB) (squares) and RMSE (circles). Zero is marked by the vertical line. Plot (c) Vertical profile of the box-average observed $\sigma$ (triangles) (using equations (12) and (15)) and the box-average $\Delta T$ (diamonds) due to the quantisation error (using equations (16) and (17)). Plot (d) depicts the results of plot (c) against the box-average $M$ reported by Mode-S EHS.
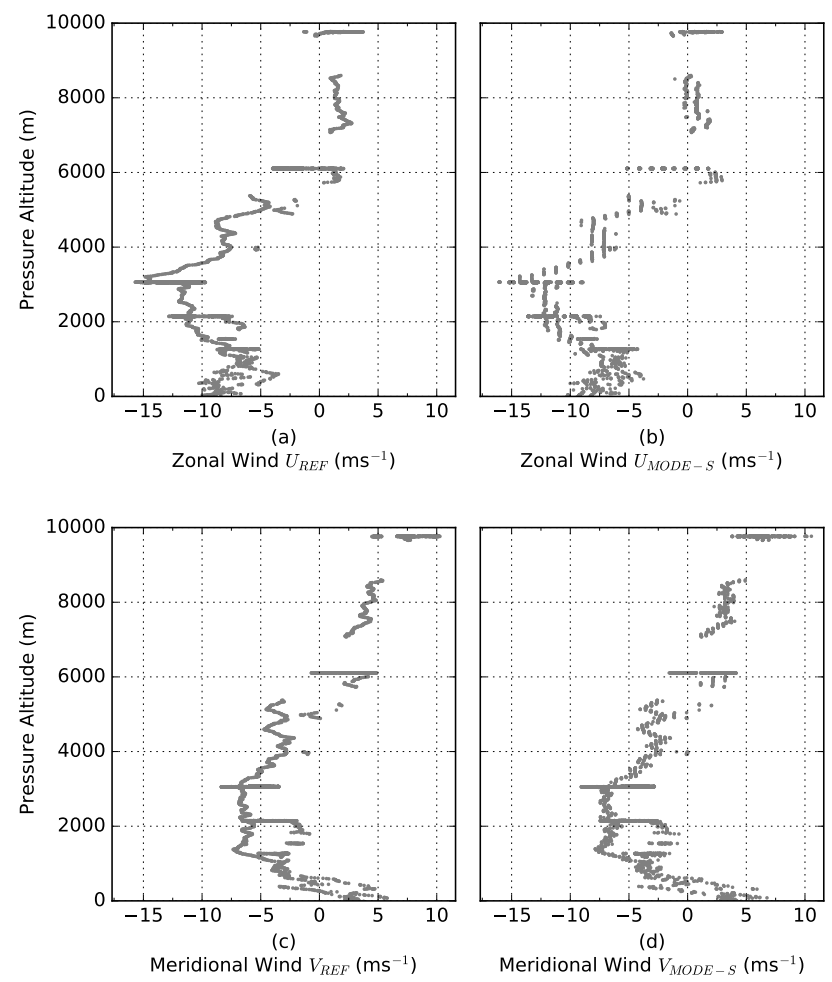

Figure 6: Flight B787 (11th July) Vertical profiles of the reference components (a) zonal $U_{R E F}$ and (c) meridional $V_{R E F}$. Vertical profile of derived components (b) zonal $U_{M o d e-S}$ and (d) meridional $V_{M o d e-S}$. The stripe effect visible in (b) and (d) is due to the reduced precision of the input data to the wind vector equations (10) and (11). This is more pronounced in the zonal component since the majority of the flight was in this direction. 

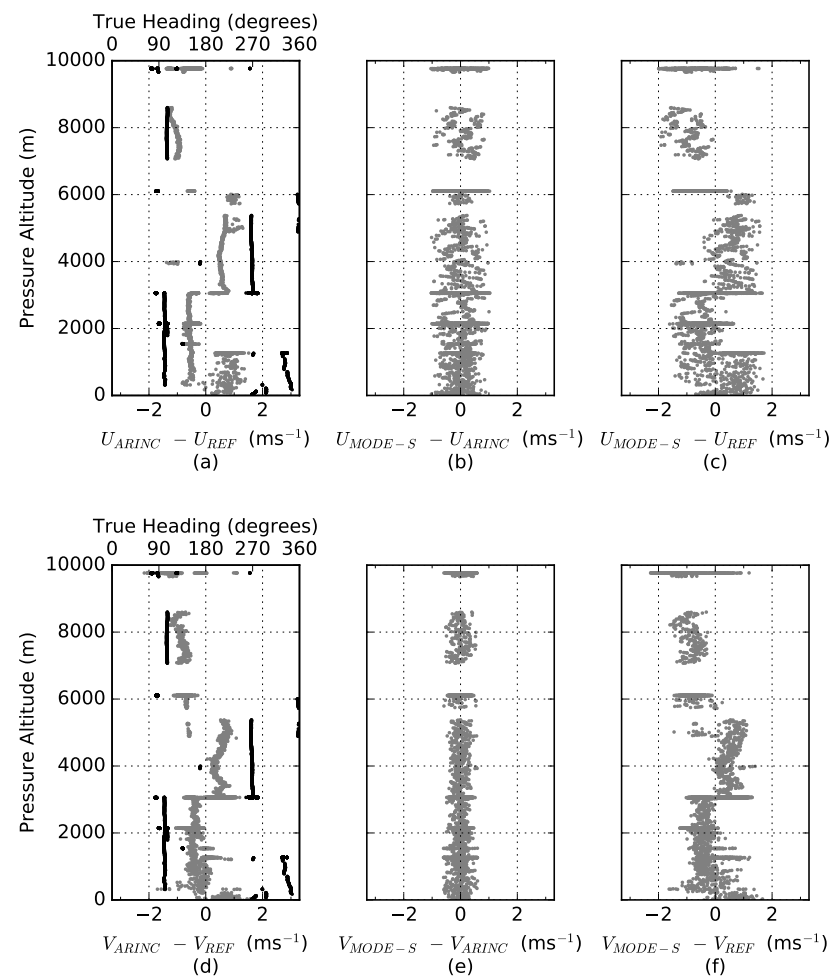

Figure 7: Flight B787 (11th July) Vertical difference profiles of the zonal $(U)$ and meridional $(V)$ wind components obtained using equations (10) and (11). The difference between the input ARINC and REF observations are shown as the grey line in plots (a) $U_{A R I N C}-U_{R E F}$ and (d) $V_{A R I N C}-V_{R E F}$. These plots also depict the aircraft's true-heading shown as the black lines referenced to the upper scale. The difference between the input ARINC and output Mode-S EHS are shown in plots (b) $U_{M o d e-S}-U_{A R I N C}$ and (e) $V_{M o d e-S}-V_{A R I N C}$. The difference between the output Mode-S EHS and REF observations are shown plots (c) $U_{M o d e-S}-U_{R E F}$ and (f) $V_{M o d e-S}-V_{R E F}$. The REF observations are derived from the FAAM's turbulence probe. To facilitate plotting, outliers greater than $3 \sigma$ from $\mu$ are not displayed, see table 8 for details.

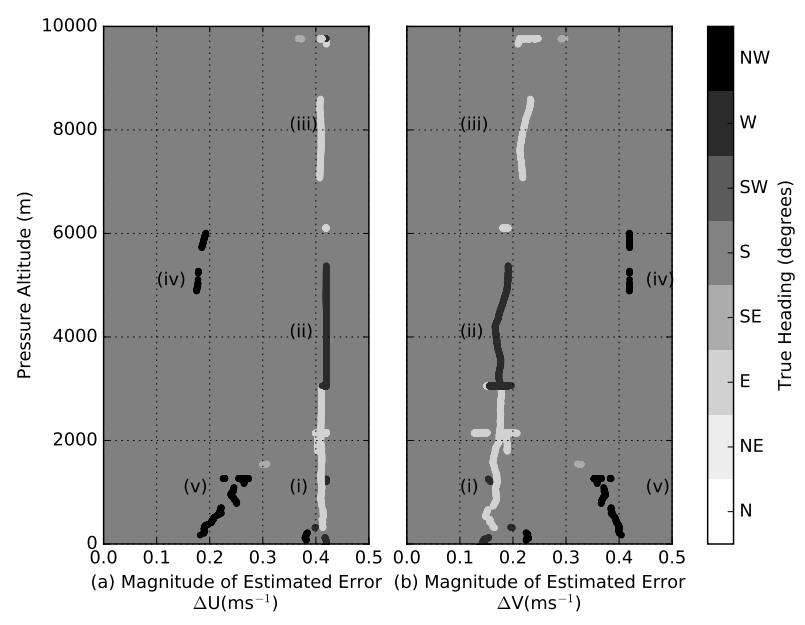

Figure 8: Flight B787 (11th July). Vertical profiles for the estimated error for the zonal, $\Delta U$ (Eq. (18) and meridional, $\Delta V$ (Eq. (19), wind components. The precision of the input data are given by the standard deviation for quantisation error, headings $\Delta \theta_{G}=\Delta \theta_{A}=0.00305 / \sqrt{12}$ radians (which is equivalent to $0.05^{\circ}$ ) and speeds $\Delta V_{G}=\Delta V_{A}=1.0289 / \sqrt{12} \mathrm{~ms}^{-1}$. The sidebar indicates the general direction of the aircraft aircraft, with true-headings binned into $45^{\circ}$ regions centred around the cardinal compass points. Regions (i) to (v) indicate the general direction of the aircraft's true-heading: (i) and (iii) East, (ii) West, (iv) North and (v) North-West. 

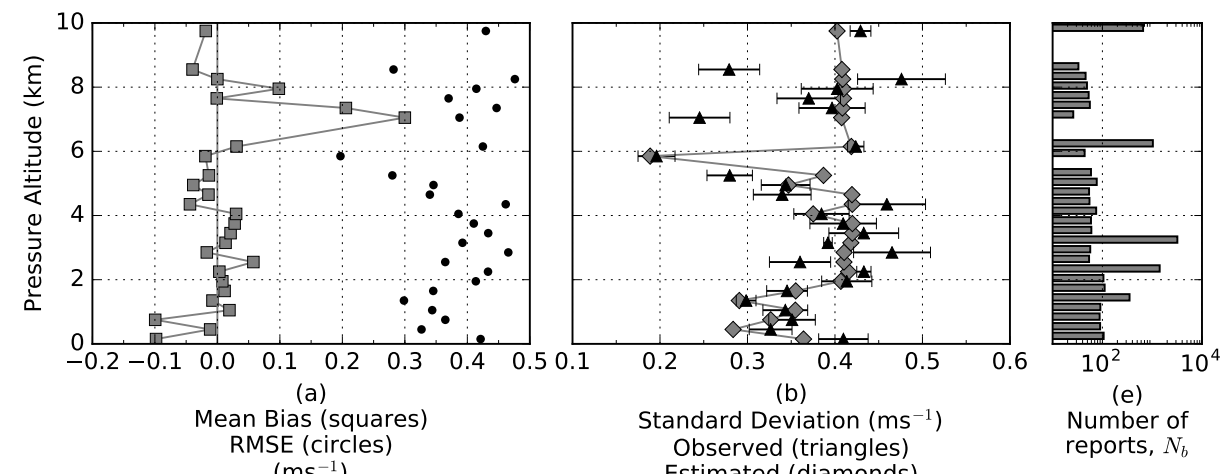

(e)

Number of RMSE (circles)

Observed (triangles)

reports, $N_{b}$
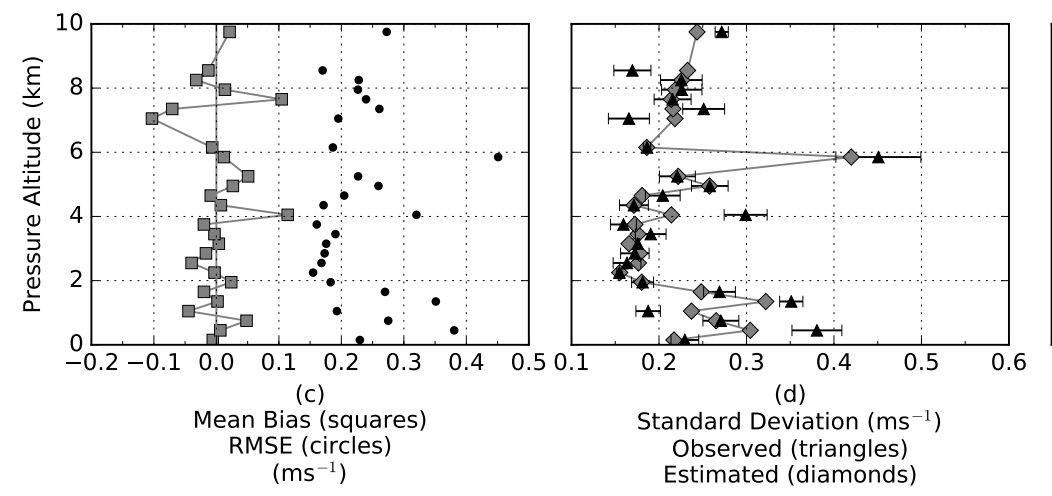

(d)

Standard Deviation $\left(\mathrm{ms}^{-1}\right)$

Observed (triangles)

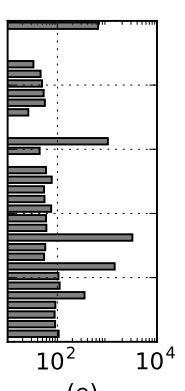

(e)

Number of

Estimated (diamonds)

Figure 9: Flight B787 (11th July) Box-average statistics for the effect of Mode-S EHS processing on the zonal $(U)$ and meridional $(V)$ wind components. Results binned by altitude, with bin heights at $0.3 \mathrm{~km}$ intervals. Plots (a) and (c) depict for the zonal and meridional winds respectively, vertical profiles of the mean bias (squares) and RMSE (circles). Zero is marked by the vertical line. Plots (b) and (d) depict for the zonal and meridional winds respectively, the vertical profiles of the box-average observed $\sigma$ (triangles) using Eq. (12) and box-average estimated component wind speed error (diamonds) due to the quantisation error using equations (18) and (19). Plots (e) depicts the number of reports per altitude bin, $N_{b}$, expressed using a $\log _{10}$ scale. This distribution is the same for each wind component. 

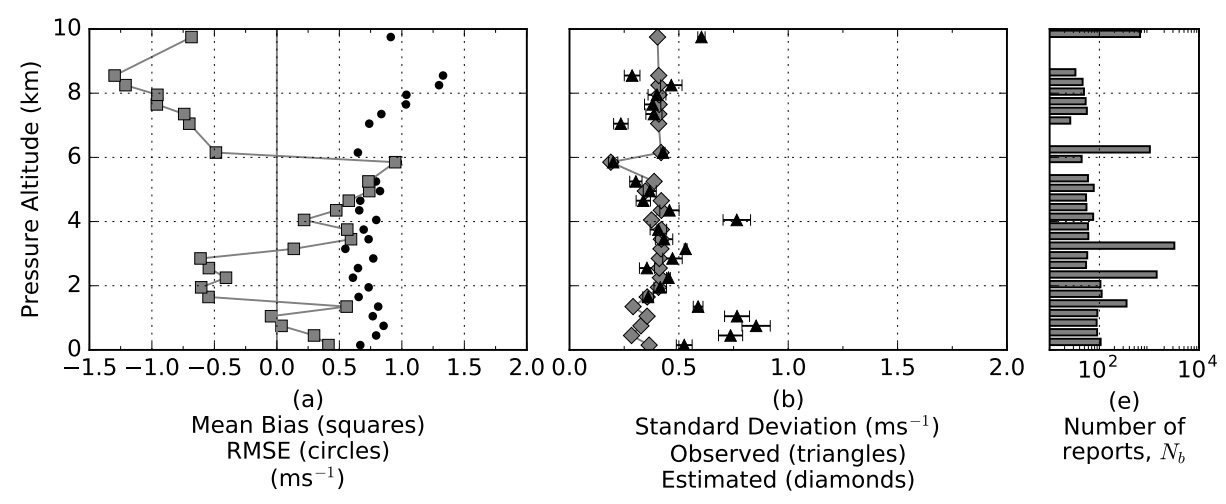

Number of $\left(\mathrm{ms}^{-1}\right)$

Estimated (diamonds)

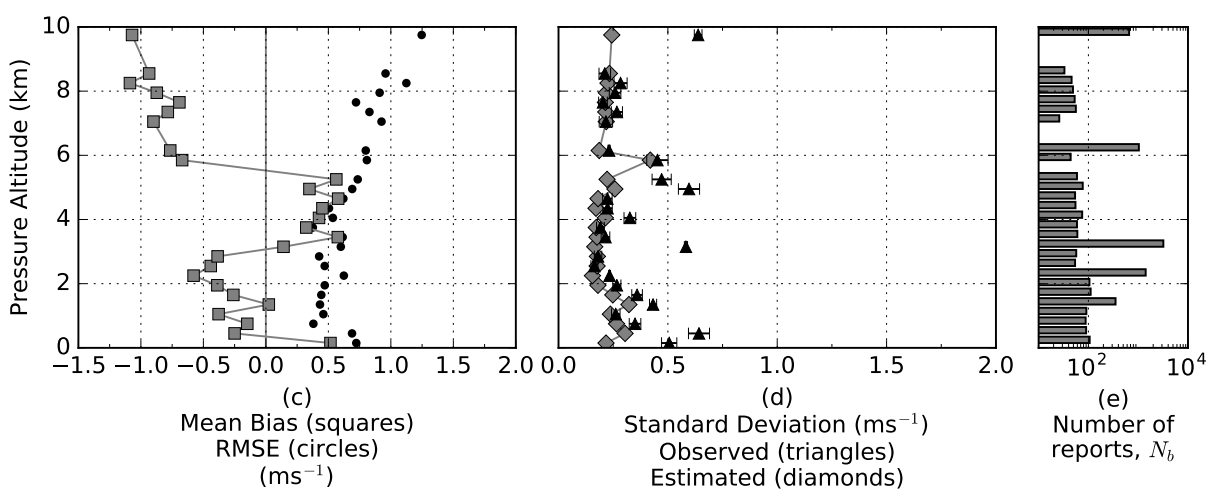

Figure 10: Flight B787 (11th July) Box-average statistics comparing Mode-S EHS processed with measured $(\mathrm{REF})$ zonal $(U)$ and meridional $(V)$ wind components. Results binned by altitude, with bin heights at $0.3 \mathrm{~km}$ intervals. The REF observations are from the FAAM's turbulence probe, located at the nose of the aircraft. Plots (a) and (c) depict for the zonal and meridional winds respectively, vertical profiles of the mean bias (squares) and RMSE (circles). Zero is marked by the vertical line. Plots (b) and (d) depict for the zonal and meridional winds respectively, the vertical profiles of the box-average observed $\sigma$ (triangles) using Eq. (12) and box-average estimated component wind speed error (diamonds) due to the quantisation error using equations (18) and (19). Plots (e) depicts the number of reports per altitude bin, $N_{b}$, expressed using a $\log _{10}$ scale. This distribution is the same for each wind component.
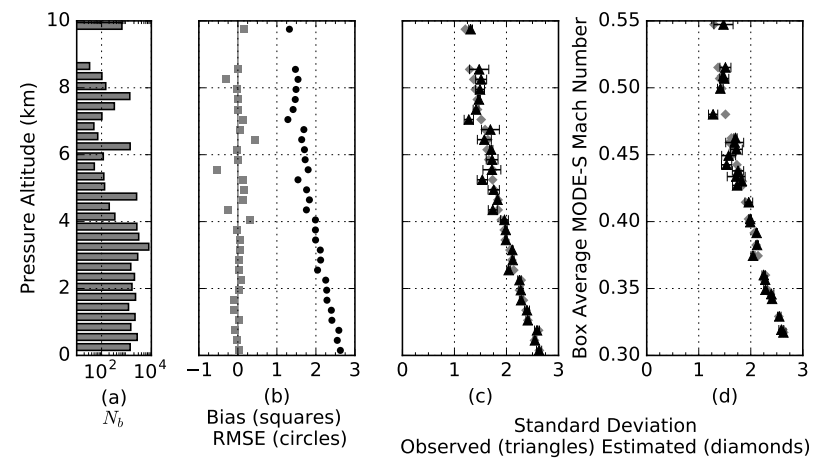

Figure 11: For all case studies listed in table 5. Box-average statistics for temperature. Results binned by altitude, with bin heights at $0.3 \mathrm{~km}$ intervals. Plot (a) is the number of reports per altitude bin, $N_{b}$, expressed using a $\log _{10}$ scale. Plot (b) vertical profile of temperature difference $\left(T_{M A C H}-T_{R E F}\right)$ mean bias (MB) (squares) and RMSE (circles). Zero is marked by the vertical line. Plot (c) Vertical profile of the box-average observed $\sigma$ (triangles) (using equations (12) and (15)) and the box-average estimated $\Delta T$ (diamonds) due to the quantisation error (using equations (16) and (17)). Plot (d) depicts the results of (c) against the box-average $M$ reported by Mode-S EHS. 

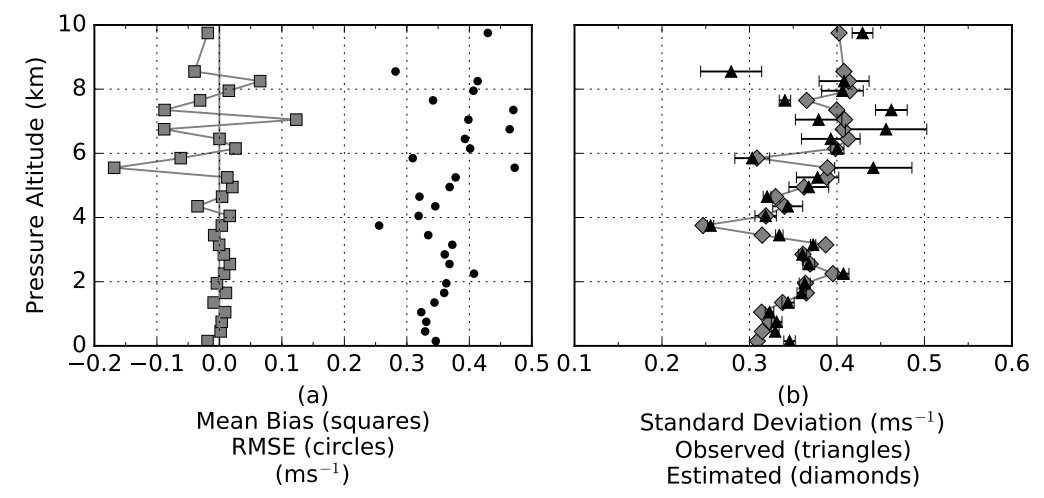

Standard Deviation ( $\mathrm{ms}^{-1}$ )

Observed (triangles)

Estimated (diamonds)

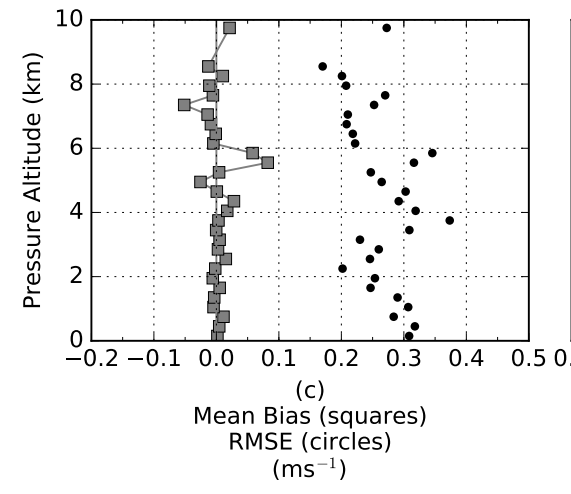

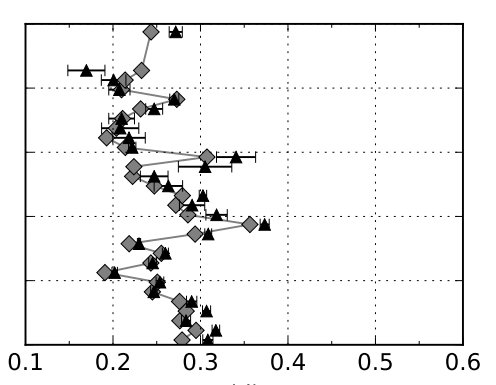

(d)

Standard Deviation $\left(\mathrm{ms}^{-1}\right)$

Observed (triangles)

Estimated (diamonds)

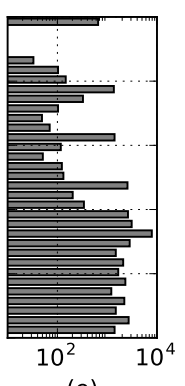

(e)

Number of reports, $N_{b}$

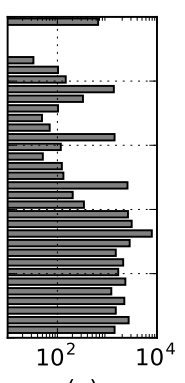

(e)

Number of reports, $N_{b}$

Figure 12: For all case studies (table 5). Box-average statistics for the effect of Mode-S EHS processing on the zonal $(U)$ and meridional $(V)$ wind components. Results binned by altitude, with bin heights at $0.3 \mathrm{~km}$ intervals. Plots (a) and (c) depict for the zonal and meridional winds respectively, vertical profiles of the mean bias (squares) and RMSE (circles). Zero is marked by the vertical line. Plots (b) and (d) depict for the zonal and meridional winds respectively, the vertical profiles of the box-average observed $\sigma$ (triangles) using Eq. (12) and box-average estimated component wind speed error (diamonds) due to the quantisation error using equations (18) and (19). Plots (e) depicts the number of reports per altitude bin, $N_{b}$, expressed using a $\log _{10}$ scale. This distribution is the same for each wind component. 


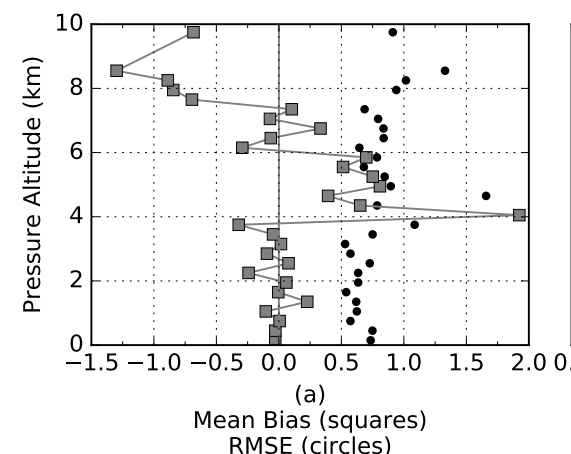
RMSE (circles)

$\left(\mathrm{ms}^{-1}\right)$

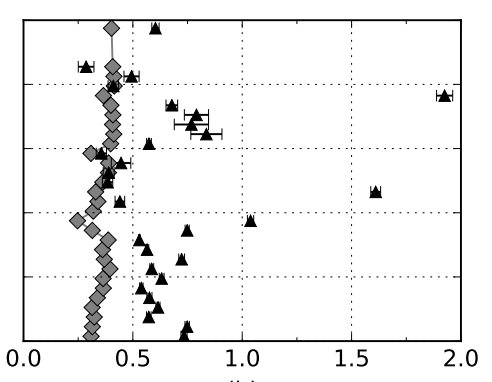

Standard Deviation $\left(\mathrm{ms}^{-1}\right)$

Observed (triangles)

Estimated (diamonds)

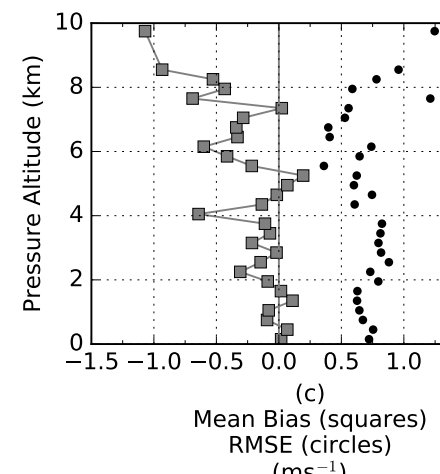

$\left(\mathrm{ms}^{-1}\right)$

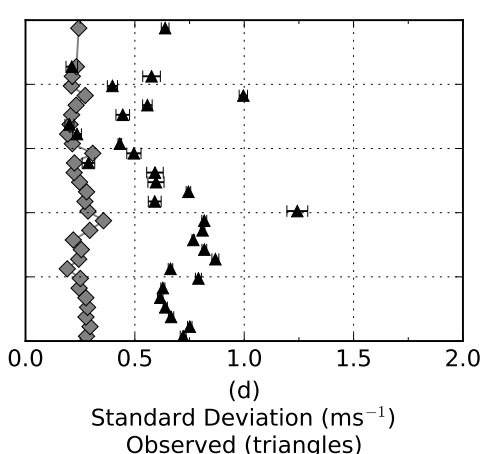

Observed (triangles) Estimated (diamonds)

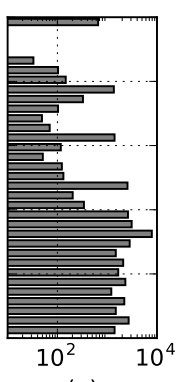

(e) Number of reports, $N_{b}$

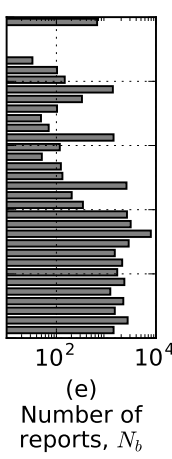

Figure 13: For all case studies (table 5). Box-average statistics comparing Mode-S EHS processed with measured $(\mathrm{REF})$ zonal $(U)$ and meridional $(V)$ wind components. Results binned by altitude, with bin heights at $0.3 \mathrm{~km}$ intervals. The REF observations are from the FAAM's turbulence probe, located at the nose of the aircraft. Plots (a) and (c) depict for the zonal and meridional winds respectively, vertical profiles of the mean bias (squares) and RMSE (circles). Zero is marked by the vertical line. Plots (b) and (d) depict for the zonal and meridional winds respectively, the vertical profiles of the box-average observed $\sigma$ (triangles) using Eq. (12) and box-average estimated component wind speed error (diamonds) due to the quantisation error using equations (18) and (19). Plots (e) depicts the number of reports per altitude bin, $N_{b}$, expressed using a $\log _{10}$ scale. This distribution is the same for each wind component. 

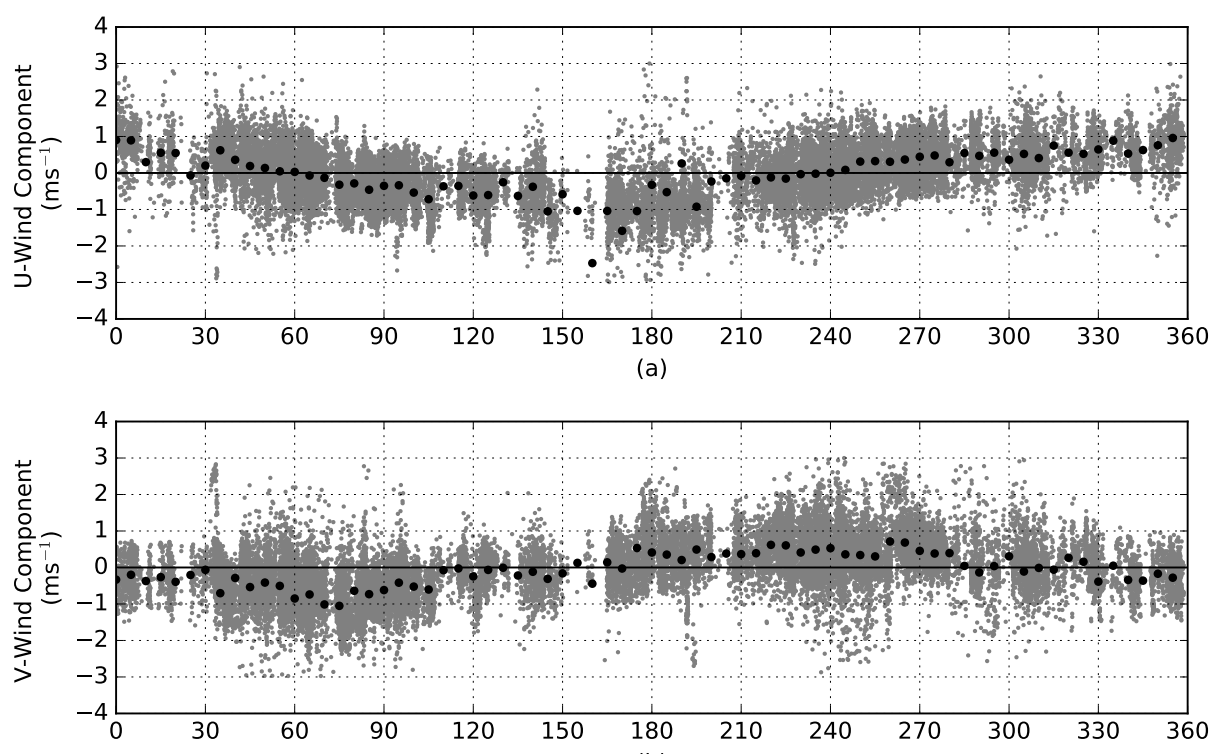

(b)

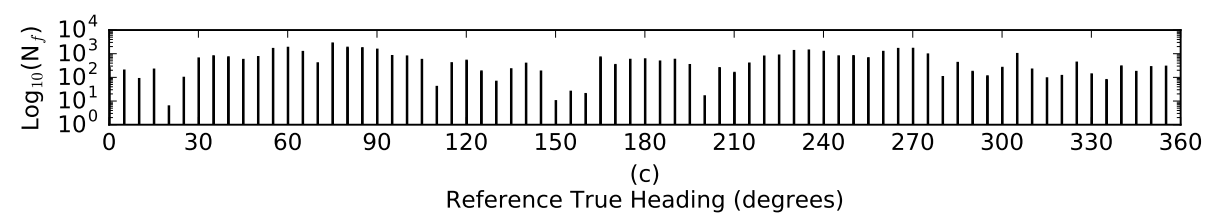

Figure 14: For all case studies. These plots suggest that there is a systematic error related to the aircraft's heading. Plot (a) depicts the zonal wind difference $\left(U_{M o d e-S}-U_{R E F}\right)$ (grey). Plot (b) depicts the meridional wind difference $\left(V_{M o d e-S}-V_{R E F}\right)$ (grey). The black circles depict the mean bias binned at $5^{\circ}$ intervals. The number of reports per bin-intervals is depicted in plot (c) as $\log _{10}\left(N_{f}\right)$. Outliers are not shown where these are greater than three times the standard deviation, $\sigma$, from the mean $\mu$. Maximum and minimum values stated but not shown. Indicated also are number of outliers removed and the total number of records. Outliers are retained for statistical results. For all records, nrecs $=42792$, for plot (a) $\mu=-0.028,3 \sigma=2.71$, $\min =-15.72$, $\max =14.64$, outliers $=289$, and for plot (b) $\mu=-0.118,3 \sigma=2.36, \min =-8.50, \max =4.66$, outliers $=77$ 
Table 1: Summary of the results from previous studies on the mean accuracy of aircraft-based observations. The table shows estimates drawn from previous studies for the overall range of the root-mean-square-errors (RMSE) for wind-speed, wind-direction, wind-vector and ambient-temperature. An em-dash $(-)$ symbol indicates the result was not stated.

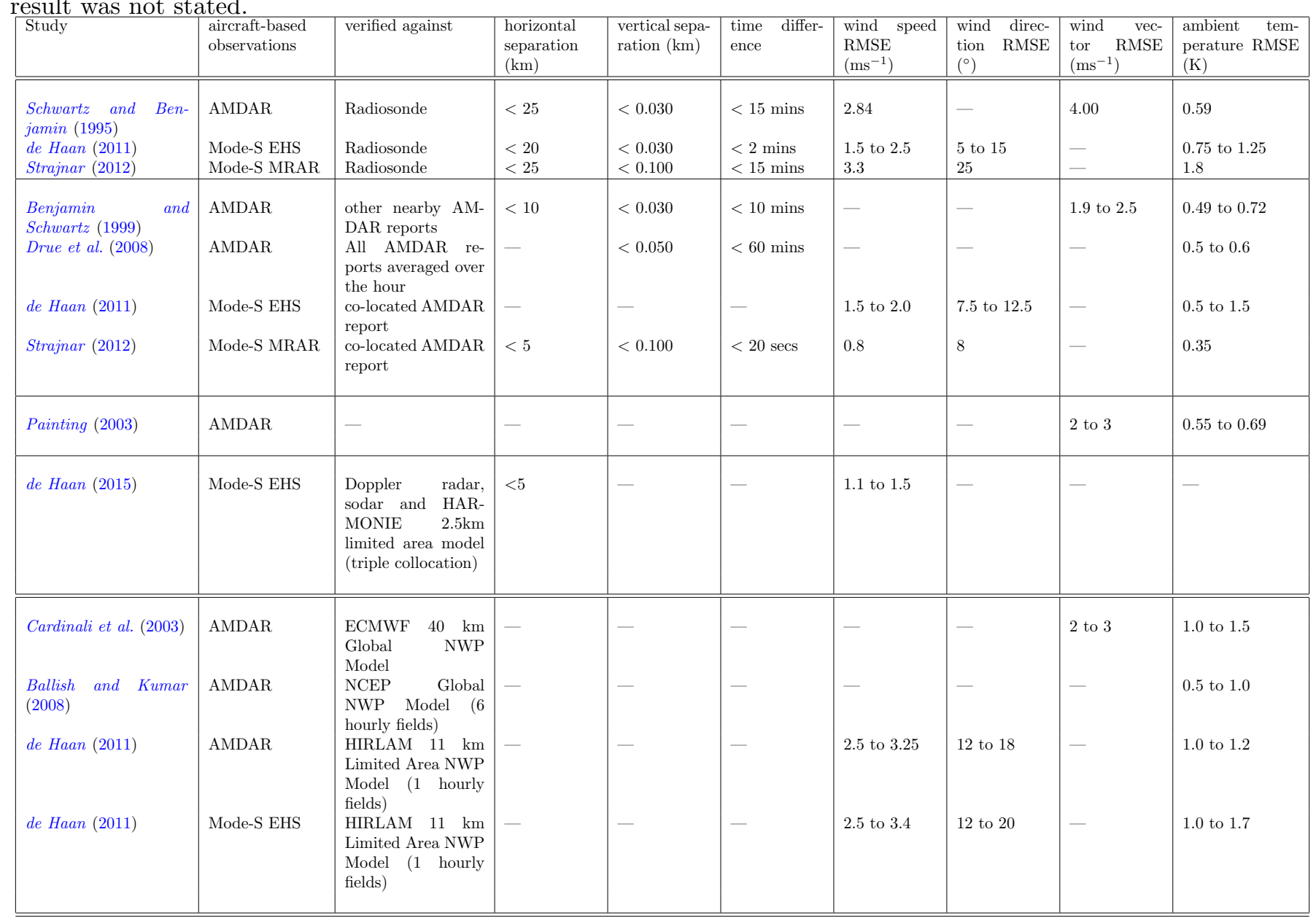

Table 2: Summary of the results from previous studies on mean bias of aircraft-based observations. The table shows estimates drawn from previous studies for the overall range of the mean bias for wind-speed, winddirection, wind-vector and ambient-temperature. An em-dash (-) symbol indicates the result was not stated.

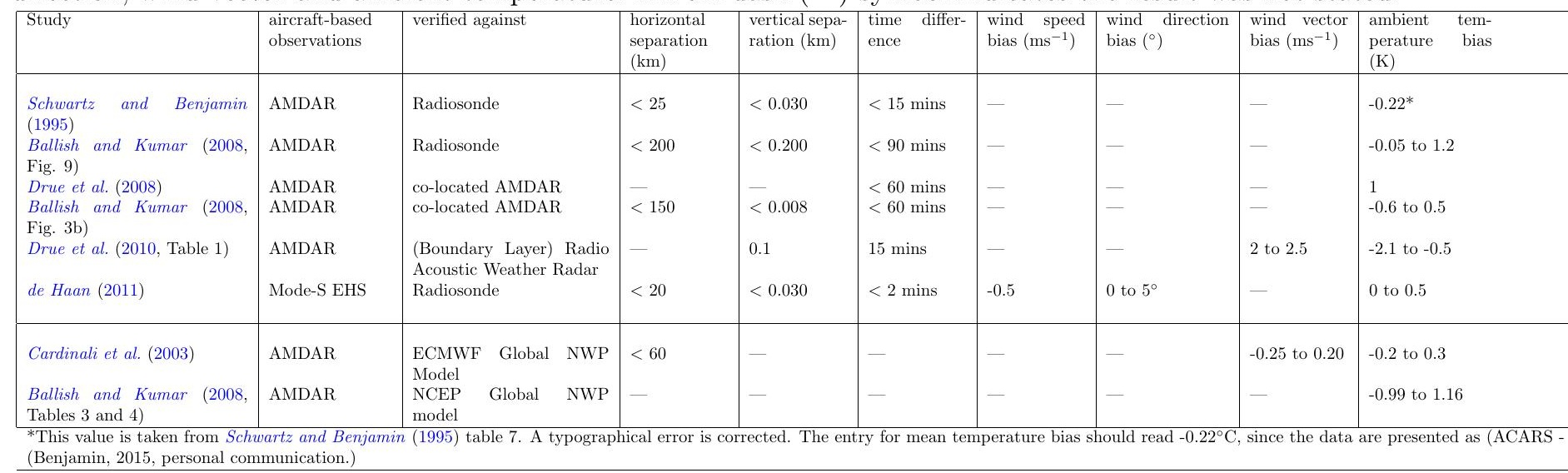


Table 3: Aircraft state parameters relevant for meteorological reporting using the ARINC-429 standard (Airlines Electronic Engineering Committee, 2004) and for transmission by Mode-S EHS (European Organisation for Civil Aviation Equipment, 2008). These data are expressed using an n-bit binary counter, where $\mathrm{n}$ is the number of binary bits. The data increment is the decimal value of the least significant bit (LSB). This is defined as the range of the reported parameter divided by the numerical range of the n-bit binary counter. The precision is taken to be $\pm 1 / 2 \times$ LSB. For example, the Mach number for Mode-S EHS is rounded to three decimal places with a precision of $\pm 1 / 2 \times 0.004$ (International Civil Aviation Organisation, 2012). Precisions for latitude, longitude and barometric pressure altitude are stated simply as expected precisions because of the complex algorithms used to encode and decode these data. Number of bits include an extra bit to represent numerical ranges with negative values.

\begin{tabular}{|c|c|c|c|c|c|c|c|c|c|c|}
\hline \multirow[b]{2}{*}{ Parameter } & \multirow[b]{2}{*}{ Symbol } & \multirow[b]{2}{*}{ Units } & \multicolumn{3}{|c|}{ Mode-S EHS } & \multicolumn{4}{|c|}{ ARINC-429 } & \multirow[b]{2}{*}{ Comment } \\
\hline & & & $\begin{array}{l}\text { Numerical } \\
\text { Range, } d\end{array}$ & $\begin{array}{c}\text { Number of } \\
\text { binary bits, } n\end{array}$ & $\begin{array}{l}\text { Data increment } \\
\text { of LSB, } \epsilon\end{array}$ & $\begin{array}{l}\text { Numerical } \\
\text { Range, } d\end{array}$ & $\begin{array}{c}\text { Number of } \\
\text { binary bits, } n\end{array}$ & $\begin{array}{l}\text { Data increment } \\
\text { of LSB, } \epsilon\end{array}$ & Label & \\
\hline Roll angle & $\theta_{R}$ & degrees & \pm 90 & 10 & 0.175 & \pm 180 & 15 & 0.01 & 325 & $\begin{array}{l}\text { Rotation of the aircraft about } \\
\text { its longitudinal axis which runs } \\
\text { from the nose to the tail. Clock- } \\
\text { wise rotation is positive. }\end{array}$ \\
\hline $\begin{array}{l}\text { True track angle } \\
\text { (ground-heading) }\end{array}$ & $\theta_{G}$ & degrees & \pm 180 & 11 & 0.175 & \pm 180 & 16 & 0.0055 & 313 & $\begin{array}{l}\text { Aircraft's direction of travel } \\
\text { along the Earth's surface re- } \\
\text { ported in degrees clockwise from } \\
\text { true north. }\end{array}$ \\
\hline Ground-speed & $V_{G}$ & knots & 0 to 2046 & 10 & 2 & 0 to 4096 & 15 & 0.125 & 312 & $\begin{array}{l}\text { Speed of the aircraft with respect } \\
\text { to the Earth's surface. }\end{array}$ \\
\hline Magnetic-heading & $\theta_{\operatorname{mag}}$ & degrees & \pm 180 & 10 & 0.175 & \pm 180 & 16 & 0.0055 & 320 & $\begin{array}{l}\text { Direction of the aircraft's longi- } \\
\text { tudinal axis in reported in de- } \\
\text { grees clockwise from magnetic } \\
\text { north. }\end{array}$ \\
\hline True-airspeed & $V_{A}$ & knots & 0 to 2046 & 10 & 2 & 0 to 2048 & 15 & 0.0625 & 210 & $\begin{array}{l}\text { Speed of the aircraft with respect } \\
\text { to the air. }\end{array}$ \\
\hline Mach number & $M$ & - & 0 to 4.096 & 10 & 0.004 & 0 to 4.096 & 16 & 0.0000625 & 205 & $\begin{array}{l}\text { Ratio of the aircraft's true- } \\
\text { airspeed to the local speed of } \\
\text { sound. }\end{array}$ \\
\hline Latitude & $\phi$ & degrees & \pm 180 & 20 & 0.00034 & \pm 180 & 21 & 0.000172 & 310 & $\begin{array}{l}\text { Geographic position at the } \\
\text { Earth's surface. Accuracy when } \\
\text { airborne is equivalent to } 5 \\
\text { metres. }\end{array}$ \\
\hline Longitude & $\lambda$ & degrees & \pm 180 & 20 & 0.00034 & \pm 180 & 21 & 0.000172 & 311 & $\begin{array}{l}\text { Geographic position at the } \\
\text { Earth's surface. Accuracy when } \\
\text { airborne is equivalent to } 5 \\
\text { metres. }\end{array}$ \\
\hline $\begin{array}{l}\text { Barometric pres- } \\
\text { sure altitude }\end{array}$ & $H$ & feet & -1000 to 126752 & 15 & 4 & 0 to 131702 & 17 & 1 & 203 & $\begin{array}{l}\text { Vertical height above mean sea } \\
\text { level under ideal conditions. Ac- } \\
\text { curacy depends on phase of } \\
\text { flight. }\end{array}$ \\
\hline Time & $\mathrm{t}$ & seconds & - & - & 0.2 & 1 & 20 & $1 \times 10^{-6}$ & 140 & $\begin{array}{l}\begin{array}{l}\text { Universal Coordinated } \\
\text { (UTC). }\end{array} \\
\text { (UTime } \\
\end{array}$ \\
\hline Static Temperature & $\overline{T_{S}}$ & Celsius & \pm 128 & 11 & 0.125 & 0 to 512 & 11 & 0.25 & 213 & $\begin{array}{l}\text { Meteorological Routine Aircraft } \\
\text { Report. }\end{array}$ \\
\hline Wind speed & $\overline{V_{w s}}$ & knots & 0 to 511 & 9 & 1 & 0 to 256 & 8 & 1 & 315 & $\begin{array}{l}\text { Meteorological Routine Aircraft } \\
\text { Report. }\end{array}$ \\
\hline $\begin{array}{l}\text { Wind direction } \\
\text { (true) }\end{array}$ & $\theta_{w d}$ & degrees & 0 to 360 & 8 & 1.41 & \pm 180 & 13 & 0.05 & 316 & $\begin{array}{l}\text { Meteorological Routine Aircraft } \\
\text { Report. }\end{array}$ \\
\hline
\end{tabular}

Table 4: Algorithm for Mode-S EHS processing. The middle column of the table contains the general algorithm for Mode-S EHS processing. The right-hand column illustrates the Mode-S EHS processing for an input value representing the ARINC Mach number, using the appropriate parameters given in table 3.

\begin{tabular}{|c|c|c|}
\hline Step Number & Algorithm & Example calculation for Mach number \\
\hline 0 & $\begin{array}{l}\text { The input values are the data, } I_{32} \text {, the data incre- } \\
\text { ment, } \epsilon \text { and the data range } d .\end{array}$ & $\begin{array}{l}\text { The input values, expressed in the unit } \\
\text { of milliMachs, are the Mach number, } \\
I_{32}=541 \text {, the data increment is } \epsilon=4 \text {, } \\
\text { the data range, } d=4096\end{array}$ \\
\hline 1 & $\begin{array}{l}\text { Compute the decimal value of the least significant } \\
\text { bit, } L S B=d / 2^{16} \text {. }\end{array}$ & $L S B=4096 / 2^{16}=0.0625$ \\
\hline 2 & $\begin{array}{l}\text { Express the input data as a } 16 \text { bit unsigned binary } \\
\text { value, } I_{16}=I_{32} / L S B \text {. }\end{array}$ & 0010000111010000 \\
\hline 3 & $\begin{array}{l}\text { Express the precision as a } 16 \text { bit unsigned binary } \\
\text { value, } P_{16}=0.5 \times \epsilon / L S B \text {. }\end{array}$ & 0000000000100000 \\
\hline 4 & $\begin{array}{l}\text { Round-up the input data by computing the sum, } \\
I_{16}+P_{16} \text {. }\end{array}$ & 0010000111110000 \\
\hline 5 & $\begin{array}{l}\text { Truncate the result to the first ten binary bits, where } \\
\wedge \text { is the logical "AND" operator, } I_{10}=\left(I_{16}+P_{16}\right) \wedge \\
(1111111111000000)\end{array}$ & 0010000111000000 \\
\hline 6 & Convert $I_{10}$ to a decimal value & $I_{10}=8640$ \\
\hline 7 & Compute the result, $R=I_{10} \times L S B$. & $R=8640 \times 0.0625$ \\
\hline 8 & Return the result, & $R=540$ milliMachs \\
\hline
\end{tabular}


Table 5: Brief description of the six flights studied in this paper. All flights took place within the United Kingdom between June and August 2013. Weather conditions for these cases are described by Eden (2013a,b)

\begin{tabular}{|c|c|c|}
\hline Date & $\begin{array}{l}\text { Flight } \\
\text { No.(f) }\end{array}$ & Description of flight \\
\hline 25 Jun & B783 & $\begin{array}{l}\text { Departure from Cranfield Airport, United Kingdom (UK) . Flight over East Anglia and nearby coast. Descent from } \\
\text { cruising altitude } 6000 \mathrm{~m} \text { to low-level } 300 \mathrm{~m} \text {. Followed by three staged ascents with level flights at } 1500 \mathrm{~m}, 2100 \mathrm{~m} \\
\text { and } 2400 \mathrm{~m} \text {, each lasting } 15 \text { minutes. Ascent to } 8200 \mathrm{~m} \text { followed by a descent to } 600 \mathrm{~m} \text {. Followed by a staged descent } \\
\text { back to Cranfield Airport. Region of flight: } 0.4^{\circ} \mathrm{E} \text { to } 2.4^{\circ} \mathrm{E} \text { and } 52.2^{\circ} \mathrm{N} \text { to } 53.4^{\circ} \mathrm{N}\end{array}$ \\
\hline 04 Jul & B785 & $\begin{array}{l}\text { Departure from Exeter Airport, UK, flying westerly to Irish sea North of Cornwall. Maintained steady altitude circling } \\
\text { in a North-South trajectory at } 4600 \mathrm{~m} \text { for an hour followed by an East-West trajectory at } 7600 \mathrm{~m} \text { for an hour. This } \\
\text { was followed by staged descents from } 9100 \mathrm{~m}, 7600 \mathrm{~m}, 6100 \mathrm{~m}, 3050 \mathrm{~m}, 300 \mathrm{~m} \text {, each stage lasting around ten minutes. } \\
\text { The low level stage at } 300 \mathrm{~m} \text { lasting around one hour with trajectories west-east over Cornwall followed by south-north } \\
\text { over Devon. Flight returned back to Exeter Airport. Region of flight: } 7.0^{\circ} \mathrm{W} \text { to } 3.5^{\circ} \mathrm{W} \text { and } 50.0^{\circ} \mathrm{N} \text { to } 51.5^{\circ} \mathrm{N}\end{array}$ \\
\hline $11 \mathrm{Jul}$ & B787 & $\begin{array}{l}\text { Departure from Exeter Airport flying north to Bristol Channel. On arriving performing East-West trajectories over } \\
\text { the Irish Sea north of Cornwall. Staged ascents } 300 \mathrm{~m}, 3000 \mathrm{~m}, 6000 \mathrm{~m}, 9800 \mathrm{~m} \text {, each phase lasting around } 45 \mathrm{minutes} \text {. } \\
\text { Followed by staged descents from } 9800 \mathrm{~m}, 3000 \mathrm{~m}, 2400 \mathrm{~m} \text {, each phase lasting around } 30 \text { minutes. Followed by staged } \\
\text { descent to Exeter Airport. Region of flight: } 7.0^{\circ} \mathrm{W} \text { to } 3.5^{\circ} \mathrm{W} \text { and } 50.0^{\circ} \mathrm{N} \text { to } 51.5^{\circ} \mathrm{N}\end{array}$ \\
\hline $25 \mathrm{Jul}$ & B789 & $\begin{array}{l}\text { Departure from Exeter Airport to Cornwall on arrival flying trajectories south-west to north-east. Staged ascents } \\
\text { from } 500 \mathrm{~m} \text { to } 3000 \mathrm{~m} \text { incrementally at } 150 \mathrm{~m} \text {, each stage lasting approximately } 5 \text { minutes. Followed by an ascent to } \\
3600 \mathrm{~m} \text { and descent to } 300 \mathrm{~m} \text { before a staged return to Exeter airport. Region of flight: } 5.0^{\circ} \mathrm{W} \text { to } 4.0^{\circ} \mathrm{W} \text { and } 50.0^{\circ} \mathrm{N} \\
\text { to } 51.5^{\circ} \mathrm{N}\end{array}$ \\
\hline $28 \mathrm{Jul}$ & B790 & $\begin{array}{l}\text { Departure from Exeter airport arriving central Cornwall in the region between Truro, Bodmin and St Austell. On } \\
\text { arrival executing North-South, East-West trajectories. Staged ascents from } 300 \mathrm{~m}, 120 \mathrm{~m}, 2700 \mathrm{~m}, 3300 \mathrm{~m}, 3800 \mathrm{~m} \text {, } \\
\text { each phase lasting approximately between } 20 \text { to } 30 \text { minutes. Final ascent to } 4500 \mathrm{~m} \text { before returning to Cranfield } \\
\text { airport. Region of flight: } 5.0^{\circ} \mathrm{W} \text { to } 4.0^{\circ} \mathrm{W} \text { and } 50.0^{\circ} \mathrm{N} \text { to } 51.2^{\circ} \mathrm{N}\end{array}$ \\
\hline $29 \mathrm{Jul}$ & B791 & $\begin{array}{l}\text { Departure from Exeter airport arriving Cornwall. On arrival executing south-west to north-east trajectories. Staged } \\
\text { ascents from } 300 \mathrm{~m}, 1500 \mathrm{~m}, 1000 \mathrm{~m}, 2700 \mathrm{~m}, 3500 \mathrm{~m}, 3800 \mathrm{~m}, 4100 \mathrm{~m}, 3800 \mathrm{~m} \text {, each phase lasting approximately } \\
\text { between } 15 \text { to } 30 \mathrm{minutes} \text {. Final descent to } 300 \mathrm{~m} \text { then ascent to } 3 \mathrm{~km} \text { before returning to Cranfield airport. Region } \\
\text { of flight: } 6.0^{\circ} \mathrm{W} \text { to } 4.0^{\circ} \mathrm{W} \text { and } 49.8^{\circ} \mathrm{N} \text { to } 51.2^{\circ} \mathrm{N}\end{array}$ \\
\hline
\end{tabular}

Table 6: Accuracy of FAAM Aircraft Parameters (Woolley, 2014b)

\begin{tabular}{l|l}
\hline Parameter & Instrument accuracy (for one standard deviation) \\
\hline \hline GPS/INS True-heading & $\pm 0.02^{\circ}$ \\
Horizontal Position & $\pm 5 \mathrm{~m}$ \\
Altitude above mean sea level & $\pm 7 \mathrm{~m}$ \\
Ground-speed & $\pm 0.07 \mathrm{~ms}^{-1}$ \\
Total air temperature (non de-iced ) & $\pm 0.3 \mathrm{~K}$ \\
Total air temperature (de-iced) & $\pm 0.3 \mathrm{~K}$ \\
Static Pressure (Corrected) & $\pm 2 \mathrm{hPa}$ \\
True-airspeed (Corrected) & $\pm 0.4 \mathrm{~ms}^{-1}$ \\
\hline
\end{tabular}

Table 7: Acceptance criteria used for filtering the aircraft data.

\begin{tabular}{|c|c|c|}
\hline Parameter & Threshold & Comment \\
\hline true-airspeed & $\begin{array}{l}25 \mathrm{~ms}^{-1}<V_{A} \leq 300 \\
\mathrm{~ms}^{-1}\end{array}$ & Gross error range check \\
\hline magnetic-heading & $0^{\circ}<\theta_{\text {mag }} \leq 360^{\circ}$ & $\begin{array}{l}\text { Aircraft heading with re- } \\
\text { spect to magnetic North }\end{array}$ \\
\hline ground-speed & $\underset{\mathrm{ms}^{-1}}{25 \mathrm{~ms}^{-1}<V_{G} \leq 425}$ & Gross error range check \\
\hline ground-heading & $0^{\circ}<\theta_{G} \leq 360^{\circ}$ & $\begin{array}{l}\text { ground-heading with re- } \\
\text { spect to geographic North }\end{array}$ \\
\hline $\begin{array}{l}\text { (Ground - Magnetic) } \\
\text { Heading }\end{array}$ & $\left|\theta_{G}-\theta_{m a g}\right|<45^{\circ}$ & Gross error range check \\
\hline $\begin{array}{l}\text { Mach Number } \\
\text { Roll Angle }\end{array}$ & $\begin{array}{l}0.000<M \leq 0.85 \\
\leq \pm 1.5^{\circ}\end{array}$ & $\begin{array}{l}\text { Gross error range check } \\
\text { threshold for stable level } \\
\text { flight }\end{array}$ \\
\hline
\end{tabular}

Table 8: Outliers not displayed in plots when the magnitude of the plotted value is greater than $3 \sigma$ from $\mu$, where $\mu$ is the mean value and $\sigma$ is the standard deviation.

\begin{tabular}{|c|c|c|c|c|c|}
\hline Figure & $\mu$ & $3 \sigma$ & Min value & Max value & Number of outliers \\
\hline \hline $7(\mathrm{a})$ & -0.077 & 1.1518 & -1.384 & 1.510 & 0 \\
$7(\mathrm{~b})$ & 0.077 & 1.213 & -1.042 & 1.031 & 0 \\
$7(\mathrm{c})$ & -0.068 & 1.932 & -1.996 & 1.714 & 6 \\
$7(\mathrm{~d})$ & -0.100 & 2.164 & -2.165 & 2.240 & 37 \\
$7(\mathrm{e})$ & -0.001 & 0.599 & -0.601 & 0.597 & 99 \\
$7(\mathrm{f})$ & -0.095 & 2.247 & -2.278 & 2.330 & 31 \\
\hline
\end{tabular}

